\title{
Antitumor profile of the PI3K inhibitor ZSTK474 in human sarcoma cell lines
}

\author{
Nachi Namatame ${ }^{1,2}$, Naomi Tamaki ${ }^{1}$, Yuya Yoshizawa ${ }^{1}$, Mutsumi Okamura ${ }^{1}$, Yumiko \\ Nishimura ${ }^{1}$, Kanami Yamazaki ${ }^{1}$, Miwa Tanaka ${ }^{3}$, Takuro Nakamura ${ }^{3}$, Kentaro Semba ${ }^{4}$, \\ Takao Yamori ${ }^{1,5}$, Shin-ichi Yaguchi ${ }^{1,2}$ and Shingo Dan ${ }^{1}$ \\ ${ }^{1}$ Division of Molecular Pharmacology, Cancer Chemotherapy Center, Japanese Foundation for Cancer Research, Tokyo, Japan \\ ${ }^{2}$ R\&D Center, Zenyaku Kogyo Co. Ltd, Tokyo, Japan \\ ${ }^{3}$ Division of Carcinogenesis, Cancer Institute, Japanese Foundation for Cancer Research, Tokyo, Japan \\ ${ }^{4}$ Department of Life Science and Medical Bioscience, School of Advanced Science and Engineering, Waseda University, Tokyo, \\ Japan \\ ${ }^{5}$ Present address: Center for Product Evaluation, Pharmaceuticals and Medical Devices Agency, Tokyo, Japan \\ Correspondence to: Shingo Dan, email: sdan@jfcr.or.jp
}

Keywords: sarcoma; PI3K; anticancer agent; cell line panel; oncogenic chromosomal translocation

Received: April 10, $2018 \quad$ Accepted: September 26, $2018 \quad$ Published: October 12, 2018

Copyright: Namatame et al. This is an open-access article distributed under the terms of the Creative Commons Attribution License 3.0 (CC BY 3.0), which permits unrestricted use, distribution, and reproduction in any medium, provided the original author and source are credited.

\section{ABSTRACT}

Treatment of patients with advanced sarcoma remains challenging due to lack of effective medicine, with the development of novel drugs being of keen interest. A pan-PI3K inhibitor, ZSTK474, has been evaluated in clinical trials against a range of advanced solid tumors, with clinical benefit shown in sarcoma patients. In the present study, we developed a panel of $\mathbf{1 4}$ human sarcoma cell lines and investigated the antitumor effect of 24 anticancer agents including ZSTK474, other PI3K inhibitors, and those clinically used for sarcoma treatment. ZSTK474 exhibited a similar antiproliferative profile to other PI3K inhibitors but was clearly different from the other drugs examined. Indeed, ZSTK474 inhibited PI3K-downstream pathways, in parallel to growth inhibition, in all cell lines examined, showing proof-of-concept of PI3K inhibition. In addition, ZSTK474 induced apoptosis selectively in Ewing's sarcoma (RD-ES and A673), alveolar rhabdomyosarcoma (SJCRH30) and synovial sarcoma (SYO-1, Aska-SS and Yamato-SS) cell lines, all of which harbor chromosomal translocation and resulting oncogenic fusion genes, EWSR1-FLI1, PAX3-FOXO1 and SS18-SSX, respectively. Finally, animal experiments confirmed the antitumor activity of ZSTK474 in vivo, with superior efficacy observed in translocation-positive cells. These results suggest that ZSTK474 could be a promising drug candidate for treating sarcomas, especially those harboring chromosomal translocation.

\section{INTRODUCTION}

Sarcomas are rare malignant tumors of mesenchymal origin, such as muscle, fat, bone and other connective tissues, with $>50$ different subtypes reported to date [1]. It is estimated about 13,000 cases of soft tissue and bone sarcoma are diagnosed per year in the United States [2, 3], with morbidity due to sarcomas found to be higher in children and young adults than in adults. There are two genetically characterized groups in sarcomas $[4,5]$; one is characterized by a specific chromosomal translocation event on a background of relatively few other chromosomal changes, which is represented by Ewing's sarcoma (ES) accompanied by the fusion of the EWSR1 (Ewing sarcoma region 1, also called $E W S$ ) gene and one of the ETS transcriptional factor genes (FLII or ERG) [6] and synovial sarcoma (SS) accompanied by the fusion of the SS18 (Synovial Sarcoma Translocation, Chromosome 18, also called SYT) gene and one of the SSX (Synovial Sarcoma, $\mathrm{X}$ Breakpoint) genes (SSX1, SSX2 or $S S X 4)$ [7-9]. These 
fusion gene products have a strong transformation activity, with the growth and survival of the cells containing these become exclusively dependent on the particular fusion [10-12]. Another group is consisted of sarcomas harboring complex karyotypic abnormalities, accompanied by multiple gene mutations, gene amplifications and chromosomal aberrations, which frequently include the impairment of cell cycle checkpoint genes [13].

Although several animal models and patient-derived xenograft models have been established to understand the molecular mechanism underlying sarcoma development, few therapeutics options are available thus far due to its complex character [4]. The primary approach for treating sarcomas is surgical resection, while systemic therapy is needed for patients with inoperable sarcoma or with metastasis. For chemosensitive sarcomas which are histologically diagnosed as small round cell sarcomas, doxorubicin and ifosfamide are applicable; however, the effectiveness of such treatments are limited $[14,15]$. In the last decade, novel targeted agents have been developed to specifically address particular biological mechanisms identified for distinct subsets of sarcoma $[13,16]$. Pazopanib was the first molecularly targeted agent approved for sarcoma treatment on the basis of modest benefit shown in the PALETTE study [17], with other small molecule inhibitors being examined in both preclinical and early phase clinical trials [18-21].

We previously established a panel of 39 human cancer cell lines (JFCR39) composed of various carcinoma types [22-24]. The JFCR39 panel, as well as the NCI60 set developed by the National Cancer Institute [25], has been used as an in vitro tool to identify novel antitumor agents and predict modes of action, as well as to identify predictive biomarkers relating to antitumor efficacy. "Fingerprints" are defined as the patterns of differential drug efficacy across the panel of cell lines, and have been found to be reflective of mode of action. Indeed, the mode of action of novel anticancer compounds could be predicted by correlation analysis of its fingerprint to those of reference compounds via a bioinformatic approach called COMPARE [26]. Using this system, we previously identified a novel phosphatidylinositol-3 kinase (PI3K) inhibitor, ZSTK474, by similarity to a known PI3K inhibitor, LY294002 [27]. This compound has been shown to exert a broad spectrum of antitumour activity across the panel of cell lines tested in vitro and in vivo [28-30]. Clinical trials of ZSTK474 performed in the U.S.A. revealed that it was well-tolerated, with nine of the 39 recipients exhibiting stable disease (SD) lasting for $>$ eight weeks of which four of these, including three sarcoma patients, had SD for an extended period (for $>16$ weeks) [31]. Interestingly, there were four sarcoma recipients in the overall cohort and three of these were included in the prolonged SD group, suggesting that ZSTK474 could be useful in sarcoma therapy. We had previously been studying at a preclinical level the antitumor effect of ZSTK474 against various carcinoma cell lines derived from different organs, albeit not sarcoma cell lines. The above-mentioned clinical trial results prompted us to examine the antitumor profile of ZSTK474 in sarcoma cell lines from various origins in preclinical models.

In the present study, we characterized the antitumor profile of ZSTK474 in sarcoma cells via the use of a cell line panel approach, akin to JFCR39. We collected 14 commercially-available sarcoma cell lines from various origins and established a sarcoma panel. A total of 24 anticancer agents including ZSTK474, other PI3K inhibitors, and those clinically used for sarcoma treatment were examined with respect to their antitumor profiles across the panel of sarcoma cell lines in terms of effects on tumor growth, PI3K-downstream signaling pathway alterations and apoptosis induction in vitro and in vivo. These profiles were then compared to genetic backgrounds of sarcoma cells in an attempt to identify candidate predictive markers for the antitumor efficacy of ZSTK474.

\section{RESULTS}

\section{Characterization of gene mutations and activation status of signaling proteins in the sarcoma cell line panel}

We first examined the genetic background of 14 cell lines within the sarcoma panel by amplicon sequencing. The origin and mutation status of each of the cell lines is shown in Table 1. Of note, eleven of the 14 cell lines had mutations in TP53, which was the most frequently mutated gene among the genes examined. In addition, gain of function mutations, which gave new activity or enhancement of its activity to the proteins, were commonly found in KIT (M541L, four cell lines), BRAF (V600E, three cell lines) and $N R A S(\mathrm{Q} 61 \mathrm{~K} / \mathrm{H}$, two cell lines) genes. In contrast, none of the cell lines in this panel harbored known gain of function mutations in the PIK3CA gene at the hotspot residues (E542, E545 and H1047). Missense mutations were not observed in the PTEN gene in these cell lines, while intronic deletions were observed in the HT-1080, RD and RD-ES cell lines.

We next examined the expression and the activation status of signaling proteins involved in PI3K-AKT-mTOR and RAS-MEK-ERK pathways by immunoblot analysis, as shown in Figure 1A. Baseline expression of phosphorylated AKT (S473 and T308) and S6 (S235/236) were detected in most of the cell lines examined, suggesting substantial activation of AKT consistent with previous findings [3236]. Expression of PTEN was significantly detected in nine of the cell lines, whereas it was barely detectable or absent in the remaining five cell lines.

We then investigated the association between gene mutations/expression and phosphorylation levels. Interestingly, cell lines harboring a gain of function mutation in either $N R A S, K R A S$ or $B R A F$ genes expressed 
Table 1: Panel of 14 sarcoma cell lines and their molecular profile determined by amplicon sequence

\begin{tabular}{|c|c|c|}
\hline Cell line & Reported mutations/fusion genes & Gene mutations detected by amplicon sequence \\
\hline \multicolumn{3}{|l|}{ Fibrosarcoma } \\
\hline HT-1080 & $C D K N 2 A(p .0 ?)$ & $\begin{array}{l}\text { IDH1 (R132C), NRAS (Q61K), PDGFRA (S566 } \\
\text { E571>K), PTEN (p.?), TP53 (G105fs*18), HRAS (H27H) }\end{array}$ \\
\hline SW684 & & $\begin{array}{l}A P C\left(\mathrm{E} 1494 \mathrm{fs}^{*} 19\right), C D K N 2 A(\mathrm{P} 114 \mathrm{~L}), T P 53\left(\mathrm{R} 213^{*},\right. \\
\left.\mathrm{R} 120^{*}, \mathrm{R} 81^{*}, \mathrm{G} 105 \mathrm{fs}^{*} 18, \mathrm{R} 342 \mathrm{fs}^{*} 3, \mathrm{R} 213 \mathrm{fs}^{*} 34, \mathrm{R} 342 \mathrm{fs}^{*} 3\right)\end{array}$ \\
\hline \multicolumn{3}{|l|}{ Giant cell sarcoma } \\
\hline GCT & $\begin{array}{l}C D K N 2 A(\mathrm{~L} 32 \mathrm{R}) \\
\operatorname{TP53}\left(\mathrm{Q} 317^{*}\right)\end{array}$ & $\begin{array}{l}B R A F(\mathrm{~V} 600 \mathrm{E}), J A K 3(\mathrm{~V} 221 \mathrm{I}), T P 53(\mathrm{R} 248 \mathrm{~W}, \mathrm{~N} 247 \mathrm{~N}, \\
\mathrm{R} 155 \mathrm{~W}), H R A S(\mathrm{H} 27 \mathrm{H})\end{array}$ \\
\hline \multicolumn{3}{|l|}{ Leiomyosarcoma } \\
\hline SK-UT-1 & & $\begin{array}{l}A P C(\mathrm{Q} 1096 *), P I K 3 C A(\mathrm{R} 88 \mathrm{Q}), \operatorname{SMARCB} 1(p . ?), \\
\text { TP53 (R175H, R248Q, R82H, R43H, R155Q), VHL } \\
\left(\mathrm{L} 128 \mathrm{fs}^{*} 31\right), H R A S(\mathrm{H} 27 \mathrm{H})\end{array}$ \\
\hline \multicolumn{3}{|l|}{ Rhabdomyosarcoma } \\
\hline $\begin{array}{l}\text { SJCRH30 } \\
\text { (alveolar) }\end{array}$ & $P A X 3-F O X O 1$ & $\begin{array}{l}K I T(\mathrm{M} 541 \mathrm{~L}), P D G F R A\left(\mathrm{~V} 824 \mathrm{~V}, \mathrm{~S} 566 \_\mathrm{E} 571>\mathrm{K}\right), T P 53 \\
(\mathrm{R} 273 \mathrm{C}, \mathrm{R} 280 \mathrm{~S}, \mathrm{Y} 205 \mathrm{C})\end{array}$ \\
\hline RD (embryonic) & & $\begin{array}{l}\text { NRAS }(\mathrm{Q} 61 \mathrm{H}), \text { KIT }(\mathrm{M} 541 \mathrm{~L}), \operatorname{PTEN}(p . ?), H R A S \\
(\mathrm{H} 27 \mathrm{H}), T P 53\left(\mathrm{G} 105 \mathrm{fs}^{*} 18, \mathrm{R} 248 \mathrm{fs}^{*} 97, \mathrm{M} 246\right. \\
\text { P250delMNRRP, R248W, R155W) }\end{array}$ \\
\hline \multicolumn{3}{|l|}{ Osteosarcoma } \\
\hline $\mathrm{HOS}$ & $C D K N 2 A(p .0 ?)$ & $\begin{array}{l}\text { TP53 (R156R, V157fs*13), PDGFRA (S566_E571>K), } \\
\text { HRAS (H27H) }\end{array}$ \\
\hline KHOS-240S & & TP53 (V157fs*13, R156P), HRAS (H27H) \\
\hline Saos-2 & $\begin{array}{l}\text { RB1 (p.0?) } \\
\text { TP53 (p.0?) }\end{array}$ & PDGFRA (S566_E571>K) \\
\hline \multicolumn{3}{|l|}{ Liposarcoma } \\
\hline SW872 & $\operatorname{PTEN}(p .0 ?)$ & $\begin{array}{l}A P C\left(\mathrm{E} 1494 \mathrm{fs}^{*} 19\right), B R A F(\mathrm{~V} 600 \mathrm{E}), C D K N 2 A(\mathrm{P} 135 \mathrm{~L}, \\
\left.\mathrm{R} 80^{*}\right), P D G F R A\left(\mathrm{~V} 824 \mathrm{~V}, \mathrm{~S} 566 \_\mathrm{E} 571>\mathrm{K}\right), T P 53(\mathrm{~T} 253 \mathrm{~A}, \\
\text { I251del, I251N, I251_T253delIL) }\end{array}$ \\
\hline \multicolumn{3}{|l|}{ Synovial sarcoma } \\
\hline SW982 - n & no $S S 18-S S X$ mutation was detected & $B R A F(\mathrm{~V} 600 \mathrm{E}), P D G F R A\left(\mathrm{~S} 566 \_\mathrm{E} 571>\mathrm{R}\right)$ \\
\hline \multicolumn{3}{|l|}{ Chondrosarcoma } \\
\hline SW1353 & & $\begin{array}{l}C D K N 2 A(p . ?), I D H 2(\mathrm{R} 172 \mathrm{~S}), K I T(\mathrm{M} 541 \mathrm{~L}), K R A S \\
(\mathrm{G} 12 \mathrm{~V}), \text { SMARCB1(p.?), TP53 (V203L, V157G) }\end{array}$ \\
\hline \multicolumn{3}{|l|}{ Uterine sarcoma } \\
\hline MES-SA & & KIT (M541L, K546K), HRAS (H27H), CDKN2A (p.?) \\
\hline \multicolumn{3}{|l|}{ Ewing's sarcoma } \\
\hline RD-ES & EWSR1-FLI1 & $\begin{array}{l}A P C\left(\mathrm{E} 1494 \mathrm{fs}^{*} 19\right), P D G F R A\left(\mathrm{~S} 566 \_\mathrm{E} 571>\mathrm{K}\right), T P 53 \\
(\mathrm{R} 273 \mathrm{C}), S M A R C B 1(p . ?), H R A S(\mathrm{H} 27 \mathrm{H})\end{array}$ \\
\hline
\end{tabular}

Footnote: p.0?: probably no protein is produced; p.?: protein has not been analyzed, an effect is expected but difficult to predict.

phosphorylated MEK and ERK proteins at a significantly higher level than wild-type cell lines (Figure 1B and $1 \mathrm{C}$ ), whereas no such association was observed regarding phosphorylated AKT nor S6 (data not shown). Unexpectedly, PTEN expression status did not associate with phosphorylated AKT levels; instead, it associated with phosphorylated IGF-1R levels (Figure 1D-1F). Besides those indicated above, no significant associations were found between other point mutations and the expression levels of $\mathrm{PI} \mathrm{K} / \mathrm{AKT}$ and MEK signaling proteins (data not shown). 


\section{Determination of antiproliferative efficacy patterns of PI3K inhibitors and other molecularly targeted drugs/chemotherapeutic drugs across the sarcoma cell line panel}

We next examined the antiproliferative effect of PI3K inhibitors, as well as other molecularly targeted drugs and chemotherapeutic drugs, in each of the cell lines within the sarcoma cell line panel. A total of 24 antitumor agents were tested and are listed in Table 2. Dose-response curves for each drug against all 14 cell lines is presented in Supplementary Figure 1, with the corresponding 50\% growth inhibition $\left(\mathrm{GI}_{50}\right)$ concentrations also calculated (Supplementary Table 1). Then, we performed COMPARE analysis of the $\mathrm{GI}_{50}$ patterns across the 14 cell lines, or "fingerprints", of ZSTK474 with those of other agents.

A

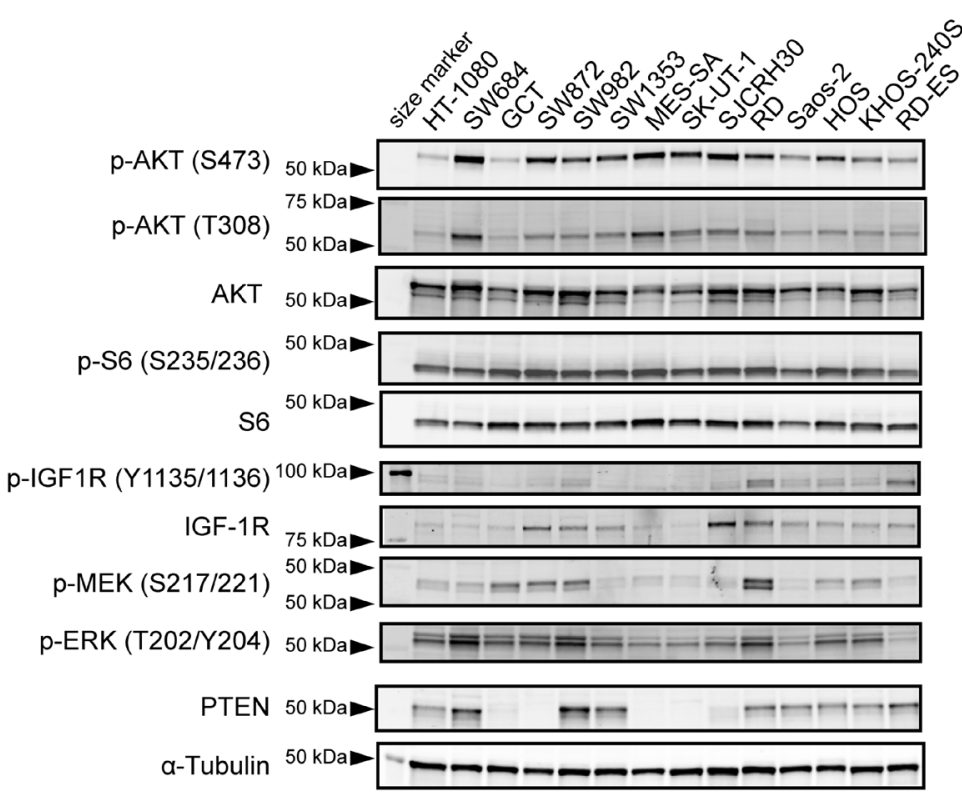

B

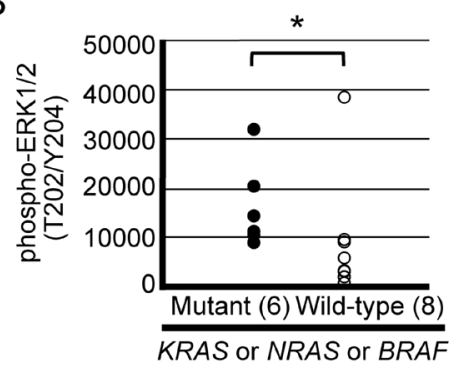

C

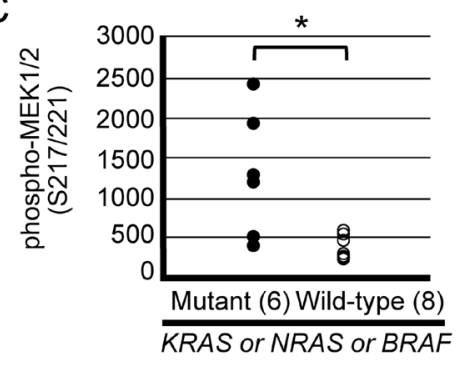

D

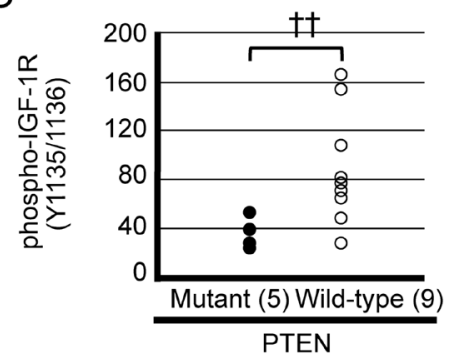

$E$

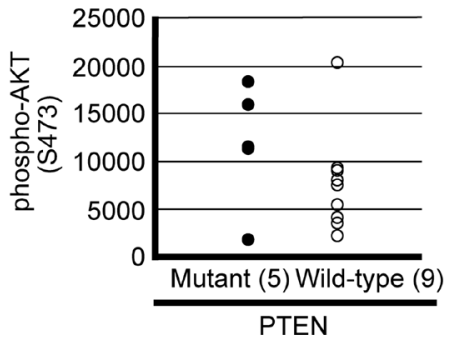

$\mathrm{F}$

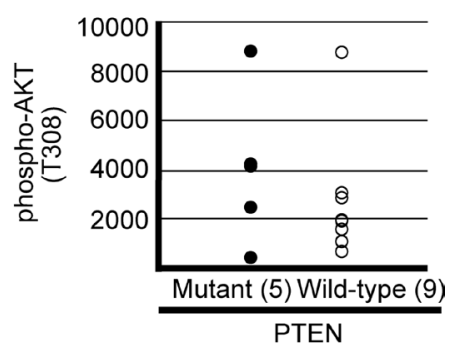

Figure 1: Baseline expression of signaling molecules within the PI3K pathway (AKT, S6, IGF-1R and PTEN) and MEK-ERK pathway in a panel of sarcoma cell lines. (A) Western blot analysis of phosphorylated AKT (S473), phosphorylated AKT (T308), total AKT, phosphorylated S6 (S235/236), total S6, phosphorylated IGF-1R (Y1135/1136), total IGF-1R, phosphorylated MEK 1/2 (S217/221), phosphorylated ERK 1/2 (T202/Y204), PTEN and $\alpha$-tubulin was performed using cellular extracts obtained from each cell line as described in the Materials and Methods section. (B-F) Detected signals were quantified by an Odyssey CLx Imaging System. Association between aberrant gene status and protein expression levels was determined by a Mann-Whitney $U$ test ( $\left.{ }^{*} p<0.05\right) /$ Welch $t$ test $\left({ }^{\dagger} p<0.01\right)$. 
Table 2: List of 24 antitumor agents examined by using sarcoma cell line panel

\begin{tabular}{|c|c|c|}
\hline Agents & Mode of action & Manufacturer \\
\hline \multicolumn{3}{|c|}{ Molecularly targeted agents } \\
\hline ZSTK474 & Pan-PI3K inhibitor & Zenyaku Kogyo Co., Ltd. \\
\hline buparlisib (BKM120) & Pan-PI3K inhibitor & Novartis International AG \\
\hline pictilisib (GDC-0941) & Pan-PI3K inhibitor & Genentech inc. \\
\hline alpelisib (BYL719) & PI3K-alpha specific inhibitor & Novartis International AG \\
\hline \multicolumn{3}{|l|}{ ZSTK534 } \\
\hline ZSTK778 & \multirow{3}{*}{ Metabolites of ZSTK474 } & \multirow{3}{*}{ Zenyaku Kogyo Co., Ltd. } \\
\hline ZSTK1741 & & \\
\hline ZSTK2209 & & \\
\hline linsitinib (OSI906) & IGF-1R inhibitor & OSI Pharmaceuticals, Inc. \\
\hline everolimus (RAD-001) & mTOR inhibitor & Novartis International AG \\
\hline selumetinib (AZD6244) & MEK1/2 inhibitor & AstraZeneca plc. \\
\hline vemurafenib & BRAF (V600E) inhibitor & Genentech inc. \\
\hline gefitinib & EGFR inhibitor & AstraZeneca plc. \\
\hline sorafenib & Multikinase inhibitor & Bayer AG \& Onyx Pharmaceuticals Inc. \\
\hline pazopanib & $\begin{array}{l}\text { Angiogenesis (multi-kinase } \\
\text { inhibitor) }\end{array}$ & Novartis International AG \\
\hline imatinib & Bcr-Abl inhibitor & Novartis International AG \\
\hline sunitinib & Multikinase inhibitor & Pfizer Inc. \\
\hline bortezomib & Proteasome inhibitor & $\begin{array}{l}\text { The Takeda Oncology Company } \\
\text { (Millennium Pharmaceuticals, Inc.) }\end{array}$ \\
\hline \multicolumn{3}{|l|}{ Chemotherapy agents } \\
\hline doxorubicin & Antineoplastic antibiotics & Kyowa Hakko Kirin Co., Ltd. \\
\hline docetaxel & Microtubule depolymerization & Sanofi S. A. \\
\hline gemcitabine & Cytosine analogue & Eli Lilly and Company \\
\hline cisplatin & DNA cross-linker & Bristol-Myers Squibb Co. \\
\hline carboplatin & DNA cross-linker & Bristol-Myers Squibb Co. \\
\hline ifosfamide & DNA alkylator & Baxter International Inc. etc. \\
\hline
\end{tabular}

As shown in Supplementary Table 2, the most highly correlated drug was ZSTK474 itself, which was done as an independent experiment. PI3K inhibitors including derivatives of ZSTK474 (ZSTK778, ZSTK534 and ZSTK1741), pictilisib (GDC-0941), buparlisib (BKM120) and alpelisib (BYL-719) were highly ranked, and everolimus, an allosteric inhibitor of mTOR, appeared after the PI3K inhibitors. Based on the correlation coefficients obtained, we performed hierarchical cluster analysis of the 24 drugs assessed (Figure 2). As expected, most of the pairs determined by two independent experiments resembled each other and were tightly clustered. Consistent with COMPARE analysis, PI3K inhibitors were sorted into one cluster and their fingerprints were clearly different from other molecularly targeted agents and chemotherapeutics. In fact, ZSTK474 was broadly effective across the 14 cell lines tested and the $\mathrm{GI}_{50}$ concentrations were distributed within a 10 -fold range $(0.1$ to $1 \mu \mathrm{M}$; Supplementary
Figures 1D and 2). In contrast, regarding the fingerprints for other molecularly targeted drugs, such as selumetinib and linsitinib, large variances were observed in respect of observed $\mathrm{GI}_{50}$ concentrations across the cell line panel. While these drugs were particularly potent against 3-4 cell lines tested, they minimally affected the remaining cell lines tested. As for other drugs tested, gemcitabine caused strong growth inhibition to most of the sarcoma cell lines; however it was ineffective against SW684 and SW1353 cells. Docetaxel, doxorubicin and bortezomib also exhibited potent growth inhibitory activity to sarcoma cells, with a cytocidal effect observed by doxorubicin and bortezomib in these assays (Supplementary Figure 1A and 1B). The multikinase inhibitors sorafenib and sunitinib showed moderate antitumor effects and exerted cytotoxicity at high concentrations (Supplementary Figure 1B and 1C).

Regarding the dendrogram of cell lines, SK-UT-1 and MES-SA, both of which were of leiomyosarcoma origin, 
and HOS and KHOS-240S, of osteosarcoma origin, were sorted into the same clusters. Other cell lines classified independently regardless of the histological categorization; for example, the fibrosarcoma cell lines HT-1080 and SW684 were sorted into separate clusters (Figure 2).

\section{Association analysis between drug sensitivity and activation status of signaling pathways}

We have thus far studied drug efficacy and the activation status of signaling pathways across the sarcoma cell line panel. Using these data, we first examined the association between fingerprints of drug efficacy and mutation status. The most prominent association identified in this screen was found between efficacy of the MEK inhibitor selumetinib and the gain of function mutation in either NRAS, KRAS or BRAF genes (Supplementary Figure 3). Notably, HT-1080 and RD cells, which both harbor a gain of function mutation on Q61 residue of $N R A S$, were extremely sensitive to selumetinib. As expected, three of the cell lines which harbored a $B R A F$ V600E mutation, namely SW982, SW872 and GCT, exhibited sensitivity to the mutant selective BRAF inhibitor, vemurafenib. In contrast, none of the gene mutations examined correlated with sensitivity to PI3K inhibitors (Supplementary Figure 2).

We secondly examined the correlation between drug efficacy and activation status; i.e., phosphorylation levels of signaling proteins. As shown in Supplementary Table 3 , none of the phosphorylated proteins, including AKT and ribosomal S6 protein, correlated with PI3K inhibitor efficacy, as examined in this study. Instead, we found significant negative correlations between phosphorylated AKT (T308) and sensitivity to pazopanib $(r=-0.70)$, docetaxel $(r=-0.63)$ or gemcitabine $(r=-0.57)$. In addition, we found a significant positive correlation between phosphorylated IGF1R and the IGF1R-TKI, linsitinib $(r=0.63)$ or the PI3K-alpha specific inhibitor alpelisib $(r=0.55)$, and between phosphorylated MEK and sensitivity to selumetinib $(r=0.66)$ or vemurafenib $(r=0.55)$.

\section{In vitro proof of concept of PI3K inhibition upon treatment with ZSTK474}

To confirm proof of concept of PI3K inhibition in vitro, we examined the phosphorylation status of PI3Kdownstream signaling molecules after treatment with ZSTK474. As shown in Figure 3, the expression levels of phosphorylated AKT (S473) and phosphorylated S6 protein (S235/236) were downregulated upon treatment with ZSTK474 at a concentration required for $50 \%$ growth inhibition in each of 14 sarcoma cell lines within $30 \mathrm{~min}$ and $6 \mathrm{~h}$, respectively. These results clearly indicated the proof of concept that ZSTK474 certainly inhibited the PI3K-downstream signaling pathway in sarcoma cells, in parallel to growth inhibition.

\section{In vivo antitumor activity of ZSTK474 in sarcoma xenograft models}

Given that PI3K inhibitors showed antiproliferative activity in sarcoma cell lines in vitro, we next exploited sarcoma xenograft models to determine antitumor activity of ZSTK474 in vivo. Of the 14 sarcoma cell lines, three cell lines (SJCHR30, SK-UT-1 and MES-SA) were subcutaneously transplantable and exhibited reproducible tumor growth in nude mice (data not shown). Therefore, we examined the effect of ZSTK474 on growth of xenografted tumors derived from these cell lines, and compared it with that affected by doxorubicin and pazopanib. As shown in Figure 4, ZSTK474 exerted comparable antitumor effects (treated/control ratio $[\mathrm{T} / \mathrm{C}]=27.4 \%$ in $\mathrm{SJCRH} 30,38.0 \%$ in SK-UT-1, 53.0\% in MES-SA and 47.0\% in MES-SA/Dx5) to both doxorubicin (T/C $=45.6 \%$ in SJCRH30, $21.3 \%$ in SK-UT-1, 53.8\% in MES-SA and 69.4\% in MES-SA/Dx5), and pazopanib $(\mathrm{T} / \mathrm{C}=53.9 \%$ in $\mathrm{SJCRH} 30,35.5 \%$ in SKUT-1, 69.2\% in MES-SA and $55.7 \%$ in MES-SA/Dx5); notably, ZSTK474 completely inhibited tumor growth of SJCRH30 xenografts. Interestingly, ZSTK474 exerted a similar antitumor effect to both MES-SA and its doxorubicinresistant variant, MES-SA/Dx5. Immunohistochemistry (IHC) revealed that ZSTK474 efficiently suppressed expression of phosphorylated S6 protein, a PI3Kdownstream signaling molecule, whereas neither doxorubicin nor pazopanib suppressed phosphorylated S6 protein. The results provided the proof of concept that ZSTK474 certainly exerted antitumor effects via inhibiting the PI3K signaling pathway in vivo, as well as in vitro.

\section{Induction of apoptosis and antitumor effects of ZSTK474 against Ewing's sarcoma cells}

We previously reported that the antitumor effect of ZSTK474 in carcinoma cells is mediated by a cytostatic effect via G1 arrest of the cell cycle, but not by a cytotoxic effect via apoptosis, using carcinoma cells from various origins both in vivo and in vitro [28-30]. In the present study, to investigate the involvement of apoptosis in the antitumor effects of ZSTK474 in sarcoma cells, 14 sarcoma cell lines were treated with ZSTK474 at a higher concentration than $\mathrm{GI}_{50}$ for an extended period (48 h, Supplementary Figure 4). Unexpectedly, emergence of cleaved poly (ADP-ribose) polymerase (PARP), one of the hallmarks of apoptosis, was observed selectively in RD-ES, an Ewing's sarcoma cell line, and SJCRH30, an alveolar rhabdomyosarcoma cell line, whereas no such event was observed in other sarcoma cell lines, except that a slight increase was observed in the Saos-2, osteosarcoma cell line. These results suggested that induction of apoptosis could be involved in the selective antitumor effect of ZSTK474 in certain types of sarcoma cells. To characterize cellular responses to ZSTK474 in Ewing's sarcoma cells in more detail, we utilized A673 


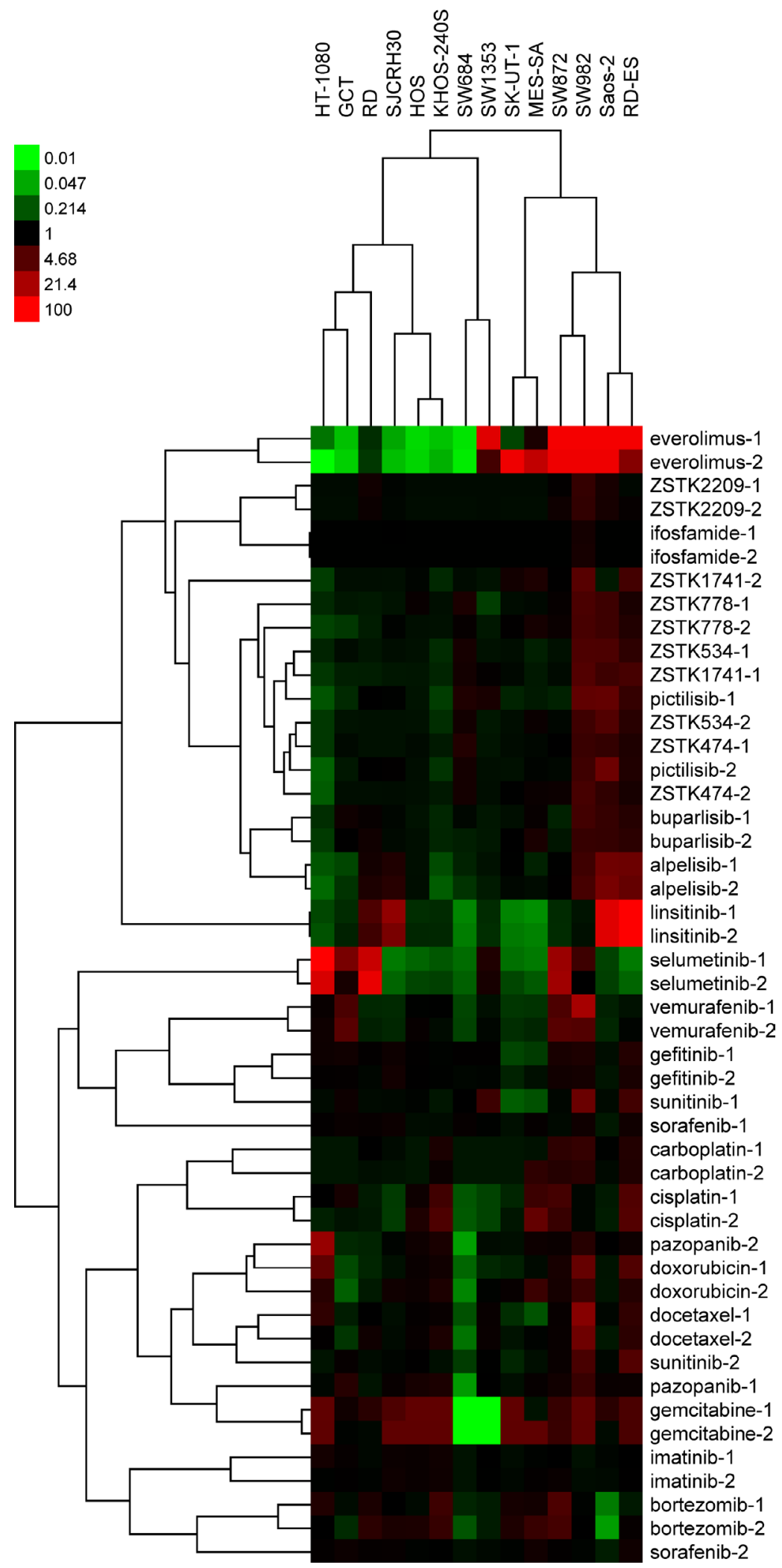

Figure 2: Hierarchical clustering of antiproliferative fingerprints of 24 anticancer compounds across 14 sarcoma cell lines and their relative antitumor activities visualized via a heatmap. $\mathrm{The}_{50} \mathrm{GI}_{50}$ concentration in each cell line was determined and log-transformed. The compounds were clustered on the basis of their correlations with other compounds (average-linkage clustered with Pearson correlation metric). Cluster analysis and visualization by heatmap was performed by using Cluster3.0/TreeView software (Stanford University). Black represents the average $\left|\log \mathrm{GI}_{50}\right|$ for each compound across the 14 cell lines assessed. Red and green represent sensitivity and resistance by 100 -fold, respectively. 


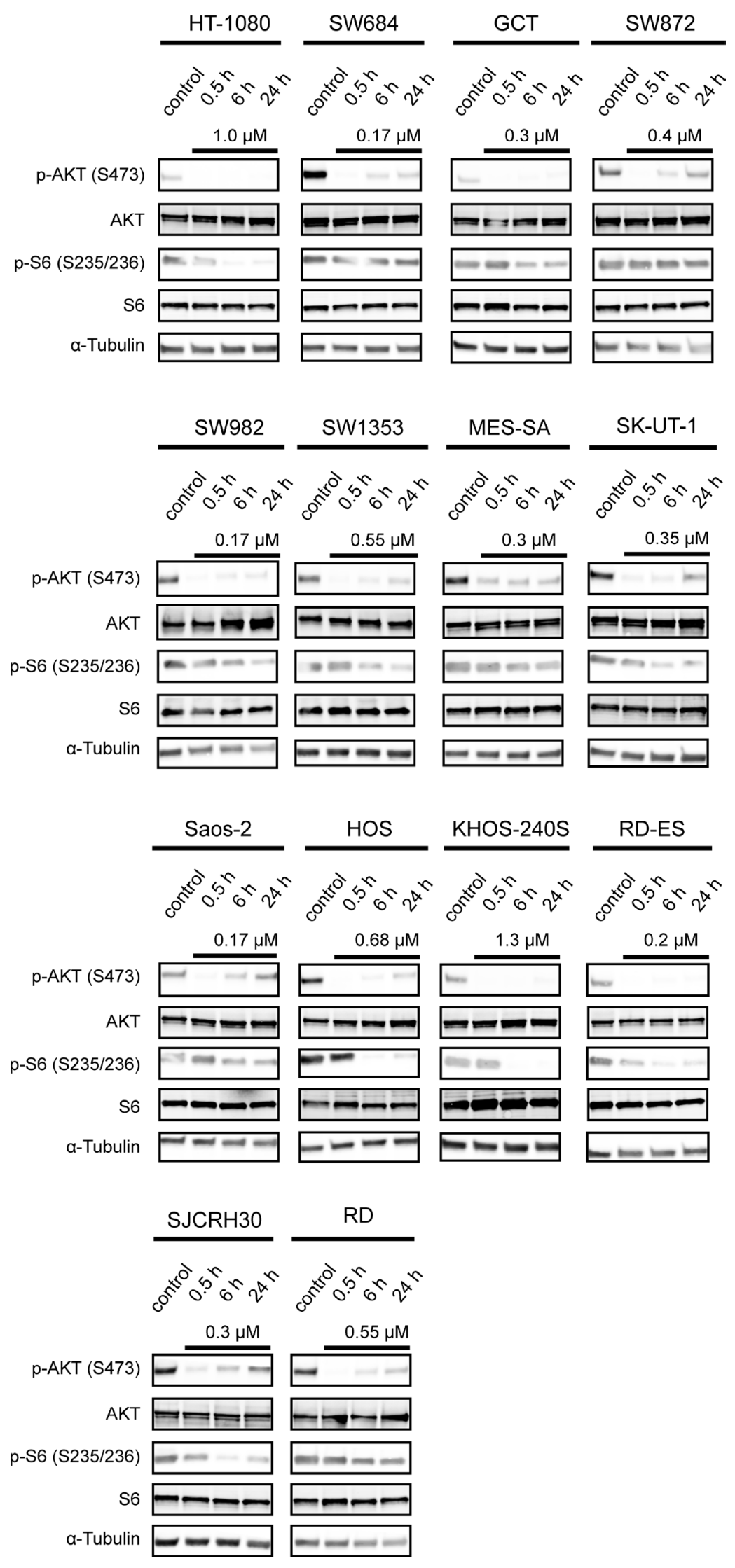

Figure 3: Effect of ZSTK474 on phosphorylation status of AKT in sarcoma cell lines in vitro. Cells were treated without or with ZSTK474 at the indicated concentrations for 0.5, 6 and $24 \mathrm{~h}$. Samples were lysed and immunoblotted to detect phosphorylated AKT (S473), total AKT, phosphorylated S6 (S235/236), total S6 and $\alpha$-tubulin as described in the Materials and Methods section. 
A SJCRH3O

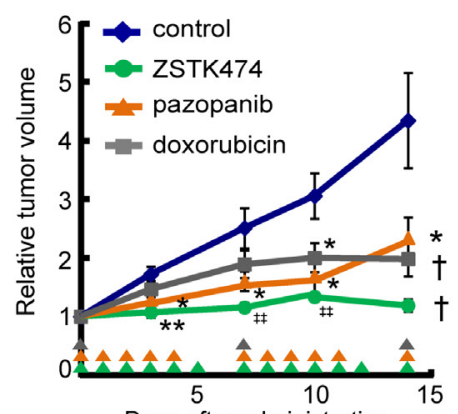

Days after administration

C SK-UT-1

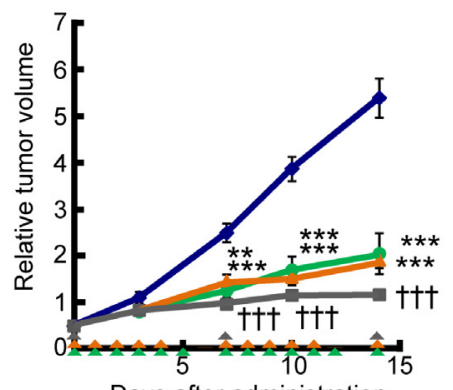

Days after administration

E MES-SA

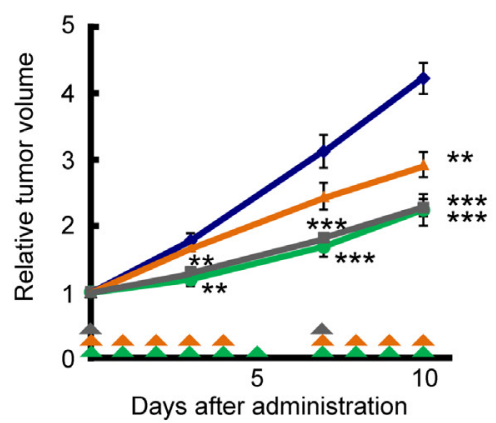

G MES-SA/Dx5

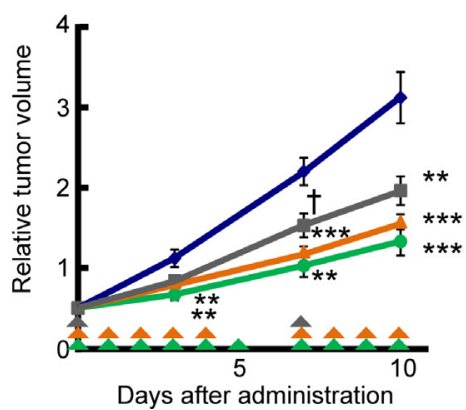

\section{B SJCRH3O}

control

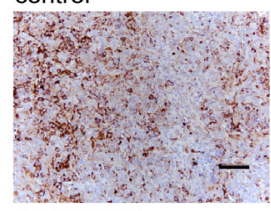

doxorubicin

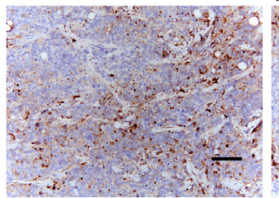

ZSTK474

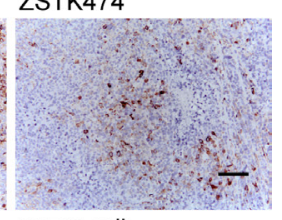

pazopanib

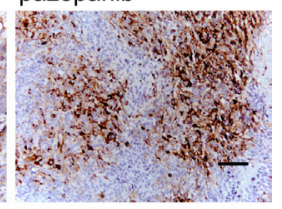

D SK-UT-1

control

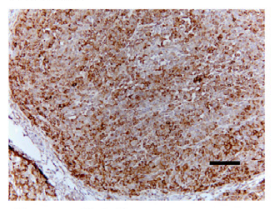

ZSTK474

doxorubicin
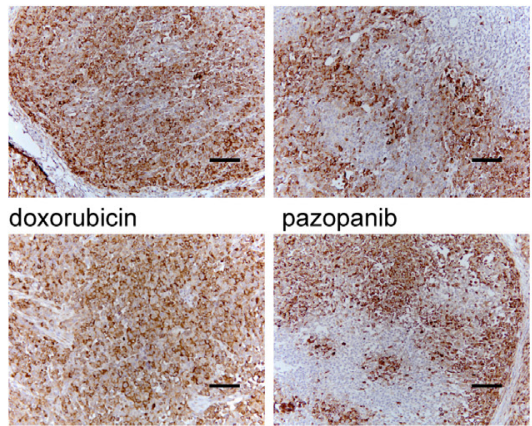

pazopanib

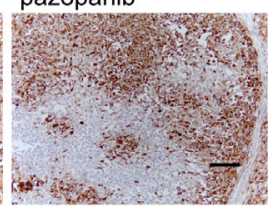

F MES-SA

control

ZSTK474
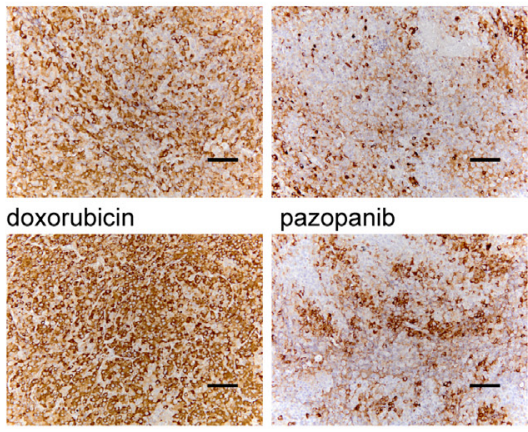

H MES-SA/Dx5

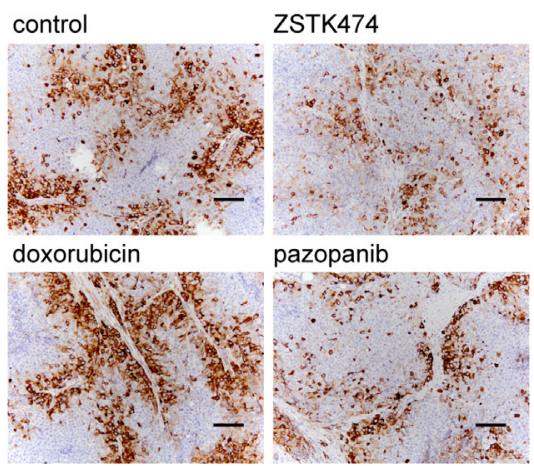

Figure 4: In vivo antitumor activity of ZSTK474 against sarcoma cell lines and the multi-drug resistant cell line (MESSA/Dx5), in comparison to conventional antitumor drugs clinically used for sarcoma. (A, C, E, G) Antitumor activity of ZSTK474, pazopanib and doxorubicin against SJCRH30 (A), SK-UT-1 (C), MES-SA (E) and MES-SA/Dx5 (G) in vivo. Mice were treated with each agent for 15 days (A, C) or 10 days (E, G). ZSTK474 (400 mg/kg of body weight/day) and pazopanib (200 mg/kg of body weight/day) were orally administrated on the days indicated by green and orange arrowheads, respectively. Doxorubicin $(10 \mathrm{mg} / \mathrm{kg}$ 
of body weight/week) was intravenously injected on the days indicated by grey arrowheads. The significance of any differences present was determined by either Student's $t$ test $\left({ }^{*} p<0.05 ;{ }^{* *} p<0.01 ;{ }^{* * *} p<0.001\right)$, Welch $t$ test $\left({ }^{\dagger} p<0.05\right.$; $\left.{ }^{\dagger \dagger} p<0.001\right)$ or Mann-Whitney $U$ test $\left({ }^{*} p<0.01\right)$. Symbols were indicated as follows: blue diamonds, control group; green circles, ZSTK474; orange triangles, pazopanib; grey squares, doxorubicin. (B, D, F, H) Phosphorylated S6 ribosomal protein (Ser235/236) was detected by immunohistochemistry in control tumor or tumors from animals treated with ZSTK474, pazopanib or doxorubicin in the case of xenografted tumors derived from SJCRH30 (B), SK-UT-1 (D), MES-SA (F) and MES-SA/Dx5 (H) cells. Tumors were resected on day 15 (SJCRH30), 16 (SK-UT-1) or 10 (MES-SA and MES-SA/Dx5). Scale bars: $100 \mu \mathrm{m}$.

and RD-ES cells to perform time course and dose-response experiments (Figure 5A, 5B). Dephosphorylation of PI3Kdownstream signaling proteins, including AKT (on S473 and T308 residues), ribosomal S6 protein (on S235/236 residues) and 4E-BP1 (on T37/46 residues) were observed within $6 \mathrm{~h}$ following ZSTK474 treatment, with effects lasting at least $48 \mathrm{~h}$ after drug exposure. Interestingly, cleaved PARP was detected within $6 \mathrm{~h}$ after exposure of ZSTK 474 at a concentration of $1 \mu \mathrm{M}$ or more, suggesting that progression of apoptosis started earlier than $6 \mathrm{~h}$. As expected, apoptotic cells increased in a dose-dependent manner in both Ewing's sarcoma cell lines following ZSTK474 treatment. From these results, we concluded that Ewing's sarcoma cells underwent apoptosis upon treatment with ZSTK474 in vitro.

\section{Effect of ZSTK474 on EWSR1-FLI1 and its transcriptional activity}

The most common chromosomal translocation found in Ewing's sarcoma, $\mathrm{t}(11 ; 22)(\mathrm{q} 24 ; \mathrm{q} 12)$, generates an aberrant transcription factor EWSR1-FLI1 fusion gene. Both the RD-ES and A673 cell lines expressed the EWSR1-FLI1 fusion protein. Previous reports have shown that protein expression of EWSR1-FLI1 fusion was attenuated upon treatment with the PI3K/mTOR dual inhibitor dactolisib (BEZ235) [37], suggesting the potential involvement of EWSR1-FLI1 in the antitumor effect of ZSTK474. However, protein expression of EWSR1-FLI1 did not attenuate upon treatment with ZSTK474 in either the RD-ES or A673 cell lines (Figure 5A, 5B). Instead, we found that ZSTK474 reduced the expression level of Id2, which was transcriptionally regulated by EWSR1-FLI1, in the Ewing's sarcoma cell lines.

Then, we next examined the effect of ZSTK474 on transcriptional activity of EWSR1-FLI1 by reporter assays. As shown in Figure 5C, the transcriptional activity from the Id2 promoter was suppressed upon treatment with ZSTK474 in a dose-dependent manner. In contrast, no such attenuation of reporter activity was observed upon ZSTK474 treatment in the EWSR1-FLI1-negative osteosarcoma cell line, HOS. This result suggested that downregulation of Id 2 protein expression observed in Ewing's sarcoma cell lines upon treatment with ZSTK474 could be mediated via transcriptional inactivation of EWSR1-FLI1 from the Id2 promoter.

\section{In vivo antitumor activity of ZSTK474 against Ewing's sarcoma xenografts}

We next examined the antitumor activity of ZSTK474 against Ewing's sarcoma cells in vivo. A673 cells were subcutaneously transplanted in nude mice, with the rapid growth of tumors subsequently observed. ZSTK474 administration for two weeks exerted a robust antitumor activity against A673-derived tumors $(\mathrm{T} / \mathrm{C}=20.8 \%$, Figure 6A). Immunoblot analysis of tumor samples resected from nude mice revealed that administration of ZSTK474 for two weeks downregulated the PI3K-downstream signaling pathway, as determined by dephosphorylation of AKT and ribosomal S6 protein (Figure 6B). Moreover, cleaved PARP was selectively detected from the samples that had been derived from ZSTK474 administratedanimals, suggesting that A673 cells underwent apoptosis upon ZSTK474 administration in vivo.

\section{Induction of apoptosis and antitumor effect of ZSTK474 on synovial sarcomas}

Induction of apoptosis in Ewing's sarcoma cell lines prompted us to examine another chromosomal translocation-positive sarcoma subtype. SYO-1, a synovial sarcoma cell line carrying SS18 (SYT)-SSX2 fusion gene, underwent apoptosis upon treatment with ZSTK474, as determined by emergence of cleaved PARP (Figure 7A). Similar results were obtained in two additional synovial sarcoma cell lines, Aska-SS and Yamato-SS (Figure 7B) [38]. We then examined the effect of ZSTK474 on SS18SSX chimera protein expressed in synovial sarcoma cell lines. In SYO-1 and Aska-SS cells, protein expression of SS18-SSX, as well as SS18, was reduced upon treatment with ZSTK474, while no significant reduction was observed in Yamato-SS cells.

We finally examined the in vivo antitumor effect of ZSTK474 against synovial sarcoma xenografts. As expected, ZSTK474 suppressed the growth of SYO-1 tumors ( $\mathrm{T} / \mathrm{C}=$ $29.2 \%$, Figure 7C). Immunoblot analysis of tumor samples revealed that ZSTK474 certainly downregulated the PI3Kdownstream signaling pathway and induced apoptosis, as determined by detection of cleaved PARP (Figure 7D). These results suggested that ZSTK474 induced apoptosis and exerted significant antitumor efficacy against synovial sarcoma, as well as Ewing's sarcoma. 


\section{Anti-angiogenic effect of ZSTK474 in vivo sarcoma xenograft model}

We previously reported that ZSTK474 exerted an antiangiogenic effect in respect of a carcinoma xenograft model in vivo [39]. We, therefore, examined the antiangiogenic effect of ZSTK474 on sarcoma xenografts by IHC analysis (Figure 8A). In the control groups, formation of CD31-positive tumor vessels was observed in the MESSA xenograft, as well as those derived from SJCRH-30, SK-UT-1, MES-SA/Dx5 and A673 cells (Supplementary Figure 5A). However, blood vessel density was significantly reduced in the tumors resected from mice after consecutive administration of ZSTK474 for two weeks. Reduction of tube formation was also observed in the SYO-1 xenograft resected from mice after ZSTK474 administration (Supplementary Figure 5B). Similar results were obtained after administration of an angiogenesis inhibitor, pazopanib; however, blood vessels remained unchanged after administration of doxorubicin. These results suggested that ZSTK474 efficiently inhibited angiogenesis in sarcoma xenografts in vivo to a similar extent to pazopanib.

\section{DISCUSSION}

In the present study, we characterized the antitumor profile of PI3K inhibitors, in particular ZSTK474 which we developed, against sarcomas in preclinical models by exploiting a panel of sarcoma cell lines derived from various origin; in this respect, effects on tumor growth,
A RD-ES

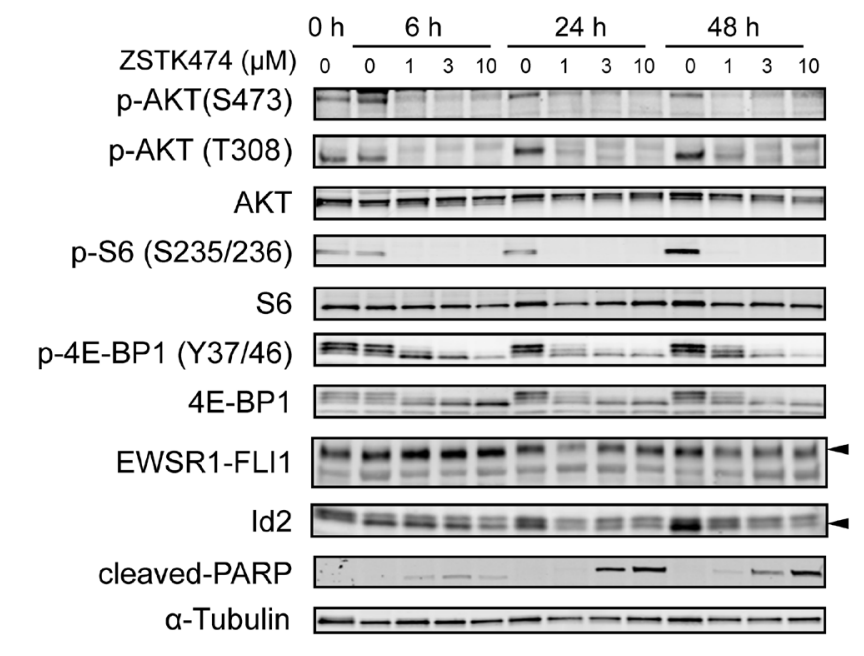

B A673

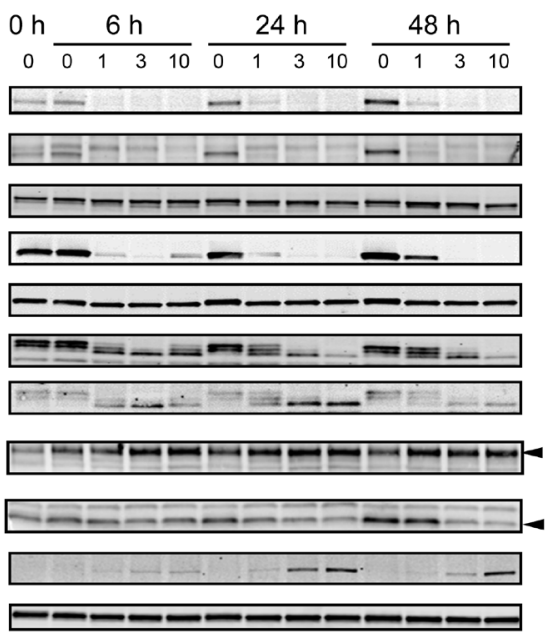

C
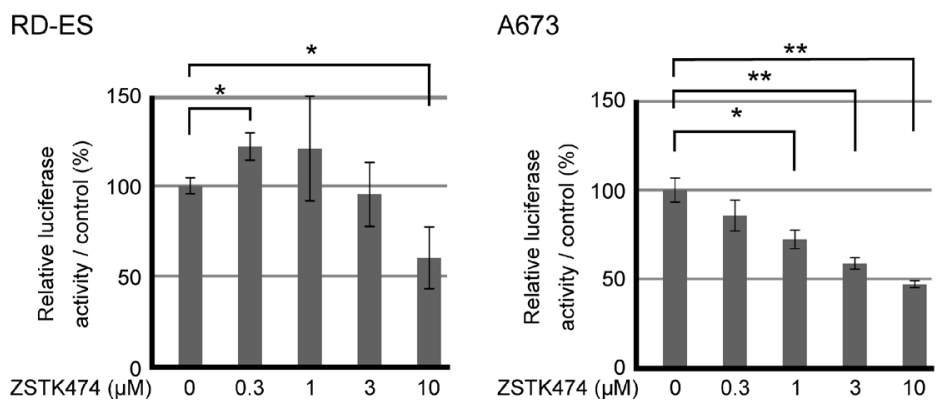

HOS

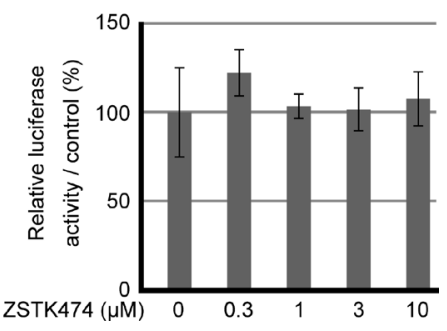

Figure 5: Effect on PI3K-downstream signaling pathway, apoptosis progression, transcriptional activity of EWSR1FLI1 and protein expression of Id2 upon treatment with ZSTK474 in Ewing's sarcoma cell lines. (A, B) RD-ES cells (A) and A673 cells (B) were treated with ZSTK474 at the specified concentrations for the indicated time. Western blot analysis of phosphorylated AKT (S473), phosphorylated AKT (T308), total AKT, phosphorylated S6 (S235/236), total S6, phosphorylated 4E-BP1 (T37/46), total 4E-BP1, EWSR1-FLI1, Id2, cleaved-PARP and $\alpha$-tubulin were performed as described in the Materials and Methods section. (C) The effect of ZSTK474 on transcriptional activity from an Id2 promoter in Ewing's sarcoma cell lines as determined by reporter assays. The Ewing's sarcoma cell lines, RD-ES and A673, and an osteosarcoma cell line, HOS, were co-transfected with the reporter plasmids pGL3-Id2-2755 (firefly luciferase) and pGL3-CMV (Renilla luciferase). Cells were treated with ZSTK474 at the indicated concentrations for $24 \mathrm{~h}$. Relative activities of firefly luciferase (derived from pGL3-Id2-2755) to Renilla luciferase (from pGL3-CMV) were calculated and normalized to drug-untreated control. Experiments were performed in triplicate. The significance of any differences present was determined by a Student's $t$ test $\left({ }^{*} p<0.05 ;{ }^{* *} p<0.01\right)$. 
PI3K-downstream signaling pathway and apoptosis induction in vitro and in vivo were assessed. COMPARE analysis and hierarchical clustering of fingerprints of tumor growth inhibition revealed that ZSTK474 highly resembled its closely related derivatives and other PI3K inhibitors in terms of effects, which was also clearly different from other molecularly-targeted agents and chemotherapeutics. The results strongly supported our hypothesis that these compounds shared a specific mode of action, i.e., similarity of their fingerprints was as a result of PI3K inhibition against sarcoma cells. In fact, ZSTK474 effectively suppressed tumor cell growth at submicromolar concentrations, with the variance of $\mathrm{GI}_{50}$ concentrations across the 14 cell lines being small (within a 10-fold range) compared to the MEK inhibitor selumetinib ( 1000-fold range). These results suggested that ZSTK474 effectively suppressed tumor growth in sarcoma cell lines irrespective of their subtype. Moreover, ZSTK474 downregulated phosphorylation of PI3K-downstream signaling factors including AKT and ribosomal S6 protein in all of the sarcoma cell line tested, suggesting proof of concept of PI3K inhibition.

In our previous study using the JFCR39 carcinoma cell line panel, gain of function mutations of the KRAS or $B R A F$ genes and overexpression of IGF1R were found to be negative predictors whereas high expression of phosphorylated AKT was observed to be a positive predictor for ZSTK474 efficacy [40]; however, neither gain of function mutations of $K R A S / N R A S / B R A F$ nor overexpression of IGFR/phosphorylated AKT displayed any significant correlation with ZSTK474 efficacy in the sarcoma panel assessed here. HT-1080, one of the less effective cell lines examined, harbored gain of function mutation of NRAS, suggesting that NRAS mutation could be involved ZSTK474 inefficacy; however, RD, another NRAS mutant cell line, responded to ZSTK474 at a moderate level. Further studies are needed to clarify whether NRAS mutation predicts ZSTK474 inefficacy. In addition, we could not determine whether $P I K 3 C A$ mutation could predict the efficacy of ZSTK474, since none of the 14 sarcoma cell lines examined harbored a gain of function mutation of PIK3CA despite gain of function mutations in this genes being commonly found in in 18 $25 \%$ of patients with liposarcomas $[41,42]$. Loss of PTEN expression seemed to have no association with ZSTK474 efficacy.

In contrast to growth inhibitory activity, apoptosis induction was selectively observed following ZSTK474 treatment. As summarized in Table 3, extensive induction of apoptosis was observed only in two of the 14 cell lines across the sarcoma panel, both of which were derived from chromosomal translocation-positive sarcomas (EWSR1-FLI1 in Ewing's sarcoma RD-ES cell line and $P A X 3-F O X O 1$ in alveolar rhabdomyosarcoma SJCRH30 cell line, respectively) $[43,44]$. We additionally examined the effect of ZSTK474 in another Ewing's sarcoma cell line, A673, and found that it also induced apoptosis in this context. Interestingly, we also examined the SYO1 cell line, which is derived from another chromosomal translocation-positive subtype, synovial sarcoma harboring
A

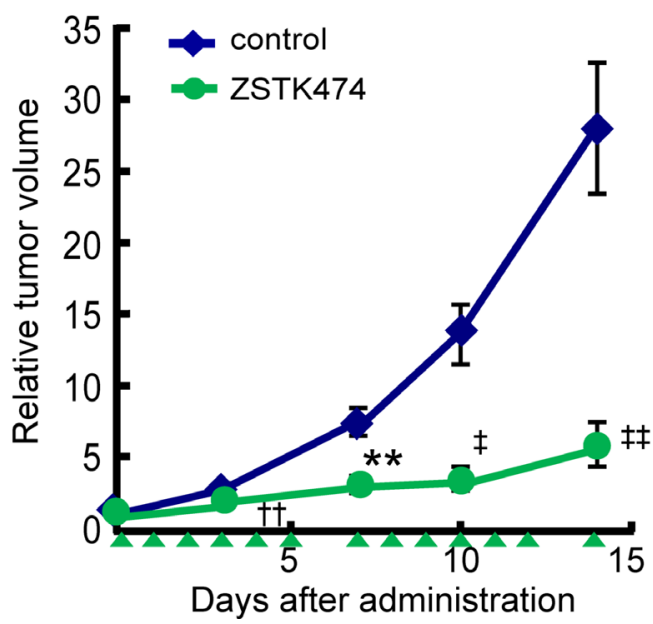

B

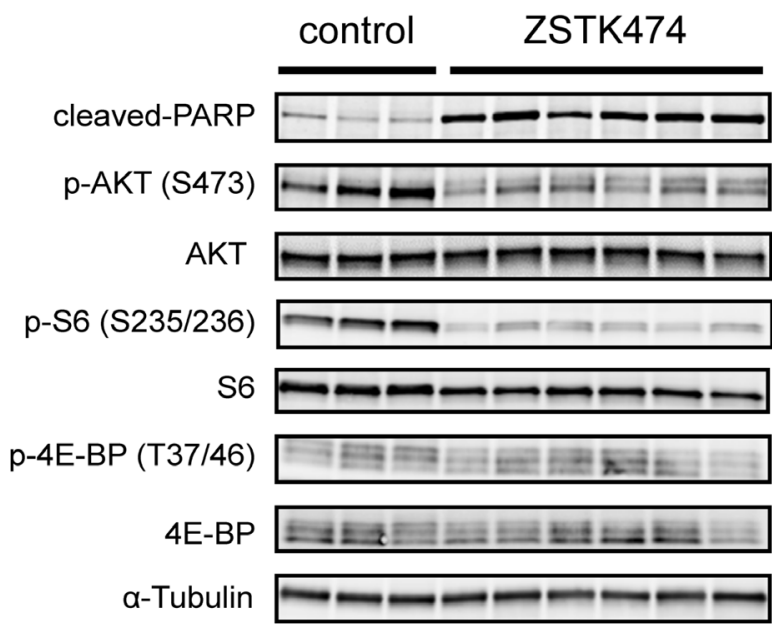

Figure 6: In vivo antitumor activity of ZSTK474 in Ewing's sarcoma cell lines. (A) Antitumor activity of ZSTK474 against A673 xenografts in vivo. Tumor-bearing mice were administered with ZSTK474 (400 mg/kg) on the days indicated by green arrowheads. Tumor volumes of each mice was measured and the mean $( \pm$ S.E.) relative tumor volume of each group was calculated. The significance of the differences present was determined by either a Student's $t$ test $\left({ }^{* *} p<0.01\right.$ ), Welch $t$ test ( $\left.{ }^{\dagger} p<0.01\right)$ or Mann-Whitney $U$ test $\left({ }^{\ddagger} p<0.05 ;{ }^{\star} p<0.01\right)$. Symbols were indicated as follows: blue diamonds, control group; green circles, ZSTK474. (B) Western blot analysis of cleaved-PARP, phosphorylated AKT (S473), total AKT, phosphorylated S6 (S235/236), total S6, phosphorylated 4E-BP1 (T37/46), total 4E-BP1 and $\alpha$-tubulin in A673 xenografted tumor samples after administration with ZSTK474. Emergence of cleaved-PARP indicated the progression of apoptosis. 
SS18-SSX2 fusion gene [45], and found that it underwent apoptosis following ZSTK474 treatment. The rest of the 12 sarcoma cell lines used in this study did not undergo apoptosis following ZSTK474 treatment, except that a slight increase was observed in the Saos-2 osteosarcoma cell line. This cell line has not been reported to express an oncogenic fusion gene generated by specific chromosomal translocation, corroborating our hypothesis that ZSTK474 could preferentially induce apoptosis in chromosomal translocation-positive sarcomas. Nevertheless, one cannot exclude the possibility of an, as yet, unknown chromosomal translocation event present in these cell lines that may confound the results.

Here, we demonstrated that ZSTK474 partially downregulated transcriptional activity of the EWSR1-FLI1 transcription factor from the Id 2 promoter via a reporter assay, and suppressed expression of the Id 2 protein in both of the Ewing's sarcoma cell lines examined. Actually, a previous study demonstrated that the EWSR1-FLI1 fusion could transform cells [46], and downregulation of EWSR1FLI1 by RNA interference could induce growth arrest in Ewing's sarcoma [47]. The precise mechanisms by which ZSTK474 downregulated EWSR1-FLI1, and by which mechanism their downregulation rendered cells susceptible to ZSTK474-induced apoptosis remains to be elucidated. Similarly, it has been reported that $S S 18-S S X$ fusion genes are capable of transforming cells and knockdown of SS18SSX expression can greatly reduce viability of synovial sarcoma cells, as determined by colony formation assays [48]. Interestingly, downregulation of SS18-SSX was

\section{B}

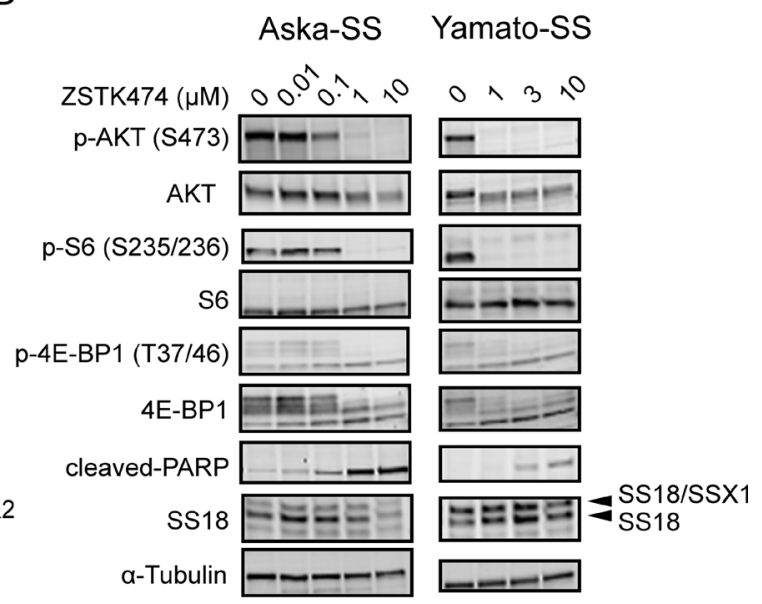

C

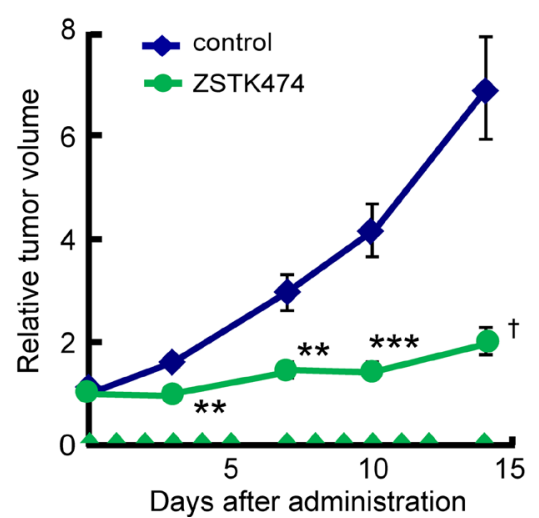

$\mathrm{D}$

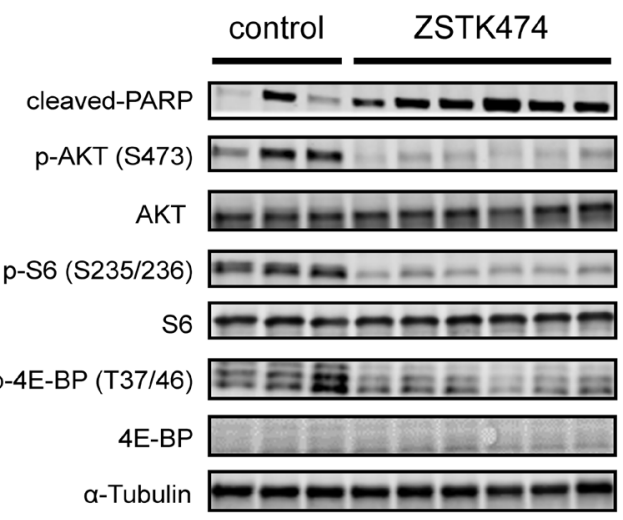

Figure 7: Effect of ZSTK474 on PI3K-downstream signaling pathway, apoptosis progression and in vivo antitumor activity in synovial sarcoma cell lines. (A, B) Synovial sarcoma cell lines, SYO-1 (A), Aska-SS and Yamato-SS (B) were treated with ZSTK474 at the indicated concentrations for the indicated time (A) or $48 \mathrm{~h}$ (B). Expression of phosphorylated AKT (Ser473), total AKT, phosphorylated S6 (Ser235/236), total S6, phosphorylated 4E-BP1 (Thr37/46), total 4E-BP1, cleaved-PARP, SS18 and $\alpha$-tubulin was examined by Western blot analysis as described in the Materials and Methods section. (C) Antitumor activity of ZSTK474 against SYO-1 xenografts in vivo. Tumor-bearing mice were administered with ZSTK474 (400 $\mathrm{mg} / \mathrm{kg})$ on the days indicated by green arrowheads. Tumor volume of each mice was measured and the mean $( \pm$ S.E.) relative tumor volume of each group were calculated. The significance of any differences present was determined by a Student's $t$ test $\left({ }^{* *} p<0.01 ;{ }^{* * *} p<0.001\right)$ or Welch $t$ test $\left({ }^{\dagger} p<0.05\right)$. Symbols were indicated as follows: blue diamonds, control group; green circles, ZSTK474. (D) Western blot analysis of cleaved-PARP, phosphorylated AKT (Ser473), total AKT, phosphorylated S6 (S235/236), total S6, phosphorylated 4E-BP1 (T37/46), total 4E-BP1 and $\alpha$-tubulin in SYO-1 xenografted tumor samples after administration with ZSTK474. 
observed in SYO-1 and Aska-SS cells, but not in YamatoSS cells upon treatment with ZSTK474 (Figure 7B). Therefore, further studies are needed to clarify the involvement of SS18-SSX downregulation in progression of apoptosis. It was reported that the synovial sarcoma Aska-SS cell line expressed an activated ALK variant and showed sensitivity to ALK inhibitors, while another synovial sarcoma cell line Yamato-SS overexpressed MET protein and exhibited sensitivity to the ALK/MET dual inhibitor, crizotinib [49, 50]. Since PI3K was shown to be regulated by both ALK and MET signals in some tumor cells [51,52], selective induction of apoptosis in synovial sarcoma cells was mediated by abrogating these aberrant tyrosine kinase signals. We also examined the expression of PAX3-FOXO1 after ZSTK474 treatment in SJCRH30 (Supplementary Figure 6). ZSTK474 did not suppress PAX3-FOXO1 expression, but electrophoretic mobility shift of PAX3-FOXO1 was observed. PAX3-FOXO1 was shown to be phosphorylated at Ser256 by AKT [53], and thus it was probably due to dephosphorylation of PAX3-FOXO1 via PI3K/AKT inhibition. However, the causality between these events observed in chromosomal translocation positive sarcoma cells and the induction of apoptosis were unclear in the context of this study. In fact, we detected neither common nor specific changes in the expression levels of Bcl-2 and IAP (inhibitor of apoptosis) family proteins in these cells upon treatment with ZSTK474 (data not shown). Further studies are needed to understand the precise mechanism of apoptosis induction in such types of sarcoma cells.
In this study, we examined the in vivo antitumor effect of ZSTK474 using various sarcoma cell lines subcutaneously xenografted in nude mice. ZSTK474 exerted a significant in vivo antitumor effect against all of sarcoma cell lines examined, comparable to the existing antitumor drugs doxorubicin and pazopanib. Of note, in vivo effect was most obvious in the three chromosomal translocation-positive sarcoma cell lines that were characterized with apoptosis induction (A673, SJCRH30 and SYO-1; Supplementary Figure 7). In addition, comparable antitumor effects were obtained with a doxorubicin-resistant MES-SA variant MESSA/Dx5 overexpressing P-glycoprotein compared to its parental cell line, indicating that ZSTK474 could be used for patients experiencing resistance to doxorubicin treatment. Moreover, we clearly demonstrated that ZSTK474 suppressed the number of CD31-positive cells and inhibited blood vessel formation within the tumors, suggestive of an anti-angiogenic effect, in agreement with our previous finding using carcinoma cells [39]. Therefore, anti-angiogenic effect of ZSTK474 could be involved in its potent antitumor activity on sarcoma.

In general, molecularly targeted drugs predominantly exert cytostatic effects on tumor cells [54]. In fact, our previous studies revealed that ZSTK474 induce G1 arrest of cell cycle but hardly induce apoptosis in various carcinoma cell lines both in vitro and in vivo $[28,30]$. In contrast, chromosomal translocation-positive sarcomas underwent apoptosis upon administration of ZSTK474 in vivo as well as in vitro, as demonstrated in
A

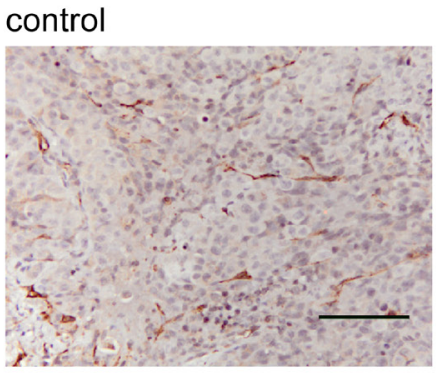

doxorubicin

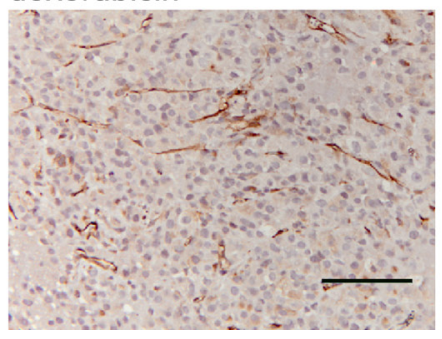

ZSTK474

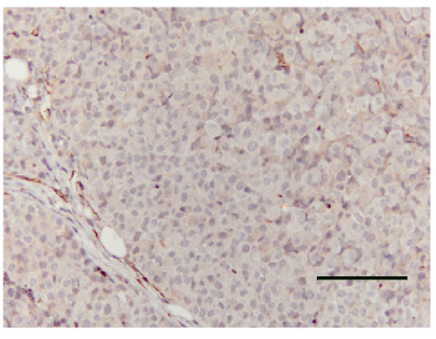

pazopanib

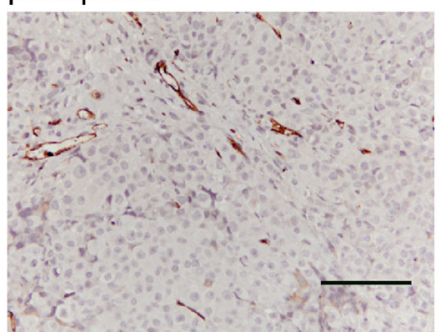

B

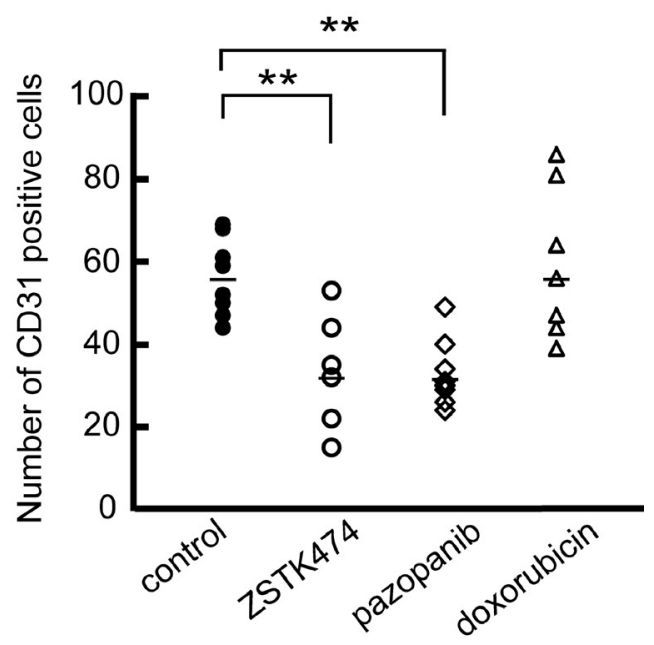

Figure 8: Anti-angiogenic activity of ZSTK474 against MES-SA xenograft in vivo. (A) Representative images of tumor vascularization in an MES-SA tumor tissue section resected from control mice or mice administered with ZSTK474, pazopanib and doxorubicin, respectively. Vascular endothelial cells were detected by immunohistochemistry using an anti-CD31 antibody. Scale bars: $100 \mu \mathrm{m}$. (B) The number of CD31-positive cells in the MES-SA tumor tissue was counted at 7 or 8 different separate positions and the average calculated. ZSTK474 effectively repressed the number of CD31 positive cells. The significance of any differences present was determined by a Student's $t$ test $\left({ }^{* *} p<0.01\right)$. 
Table 3: Summary of in vitro and in vivo antitumor activities of ZSTK474 across the sarcoma cell lines

\begin{tabular}{|c|c|c|c|c|c|c|c|c|c|}
\hline \multirow[b]{2}{*}{ Subtype } & & \multirow[b]{2}{*}{ Cell line } & \multirow[b]{2}{*}{ Fusion gene } & \multirow{2}{*}{ ב } & \multicolumn{2}{|c|}{ in vitro activities } & \multicolumn{3}{|c|}{ in vivo activities } \\
\hline & & & & & $\begin{array}{c}\mathbf{G I}_{50} \\
(\mu \mathbf{M})\end{array}$ & $\begin{array}{l}\text { Apoptosis } \\
\text { induction }\end{array}$ & T/C (\%) & $\begin{array}{l}\text { Apoptosis } \\
\text { induction }\end{array}$ & $\begin{array}{c}\text { Anti-angiogenic } \\
\text { effect }\end{array}$ \\
\hline \multirow{2}{*}{\multicolumn{2}{|c|}{ Fibrosarcoma }} & HT-1080 & - & $\bullet$ & 0.94 & - & & n.d. & \\
\hline & & SW684 & - & $\bullet$ & 0.18 & - & & n.d. & \\
\hline Giant cell sarcoma & & GCT & - & $\bullet$ & 0.41 & - & & n.d. & \\
\hline Leiomyosarcoma & & SK-UT-1 & - & $\bullet$ & 0.42 & - & 38.0 & - & $\bullet$ \\
\hline \multirow[t]{2}{*}{ Rhabdomyosarcoma } & alveolar & SJCRH30 & PAX3-FOXO1 & $\bullet$ & 0.46 & $\bullet$ & 27.4 & $\bullet$ & • \\
\hline & embryonic & $\mathrm{RD}$ & - & $\bullet$ & 0.47 & - & & n.d. & \\
\hline \multirow{3}{*}{\multicolumn{2}{|c|}{ Osteosarcoma }} & HOS & - & $\bullet$ & 0.41 & - & & n.d. & \\
\hline & & KHOS-240S & - & $\bullet$ & 0.55 & - & & n.d. & \\
\hline & & Saos-2 & - & $\bullet$ & 0.14 & $\Delta$ & & n.d. & \\
\hline Liposarcoma & & SW872 & - & $\bullet$ & 0.35 & - & & n.d. & \\
\hline \multirow{4}{*}{\multicolumn{2}{|c|}{ Synovial sarcoma }} & SW982 & - & $\bullet$ & 0.12 & - & & n.d. & \\
\hline & & SYO-1 & $S S 18-S S X 2$ & - & 0.031 & $\bullet$ & 29.2 & $\bullet$ & $\bullet$ \\
\hline & & Yamato-SS & SS18-SSX1 & - & 0.023 & $\bullet$ & & n.d. & \\
\hline & & Aska-SS & SS18-SSX1 & - & 0.0039 & - & & n.d. & \\
\hline Chondrosarcoma & & SW1353 & - & $\bullet$ & 0.50 & - & & n.d. & \\
\hline \multirow{2}{*}{\multicolumn{2}{|c|}{ Ewing's sarcoma }} & RD-ES & EWSR1-FLI1 & $\bullet$ & 0.20 & $\bullet$ & & n.d. & \\
\hline & & A673 & EWSR1-FLI1 & - & 0.32 & $\bullet$ & 20.8 & $\bullet$ & $\bullet$ \\
\hline \multirow{2}{*}{\multicolumn{2}{|c|}{ Uterine sarcoma }} & MES-SA & - & $\bullet$ & 0.40 & - & 53.0 & - & $\bullet$ \\
\hline & & MES-SA/Dx 5 & - & - & 0.31 & - & 47.0 & n.d. & - \\
\hline
\end{tabular}

$\bullet$ : yes; $\boldsymbol{\Delta}$ : marginal; -: no; n.d.: not determined.

the present study. ZSTK474 has not yet administered to patients with such types of sarcoma; but the present results suggest that ZSTK474 would exert potential clinical benefits on them via tumor shrinkage in addition to inhibition of tumor proliferation and warrant further clinical development [55].

\section{MATERIALS AND METHODS}

\section{Drugs}

Buparlisib (BKM-120) and everolimus (RAD-001) were purchased from AdooQ BioScience (Irvine, CA, USA). Sorafenib, doxorubicin and gemcitabine were purchased from Cayman Chemical Company (Ann Arbor, MI). Cisplatin, pictilisib (GDC-0941) and pazopanib were purchased from Cellagen Technology (San Diego, CA, USA). Docetaxel and selumetinib (AZD6244) were purchased from Focus Biomolecules (Plymouth Meeting, PA, USA). Carboplatin and ifosfamide were purchased from LKT Laboratories, Inc. (St. Paul, MN, USA). Alpelisib (BYL-719), vemurafenib, imatinib, sunitinib and gefitinib were purchased from Active Biochemicals Co., Ltd. (Hong Kong, China), Axon Medchem BV. (Groningen, Netherlands), BioVision Inc. (Milpitas, CA, USA), R\&D Systems, Inc. (Minneapolis, MN, USA) and Synkinase Pty Ltd. (Parkville, VIC, Australia), respectively. ZSTK474, ZSTK534, ZSTK778, ZSTK1741 and ZSTK2209 were kindly gifted from Zenyaku Kogyo Co., Ltd. For in vivo studies, a solid dispersion form of ZSTK474 was suspended with distilled water (Otsuka Pharmaceutical Factory, Inc., Tokushima, Japan). Doxorubicin was purchased from Cayman Chemical Company (Ann Arbor, MI) and dissolved with saline (Otsuka Pharmaceutical Factory, Inc., Tokushima, Japan). Pazopanib was purchased from Cellagen Technology (San Diego, CA), dissolved with DMSO for in vitro studies, and suspended with 5\% hydroxypropylmethyl cellulose (HPMC) for in vivo studies.

\section{Cell lines and cell culture}

Cell lines used in the sarcoma cell line panel assay are listed in Table 1. These cell lines were purchased from the American Type Culture Collection (Manassas, VA), and were maintained in RPMI 1640 (Wako Pure Chemical Industries Ltd., Osaka, Japan) supplemented with 5\% (v/v) fetal bovine serum (Nichirei Biosciences, Tokyo, Japan) and $1 \mu \mathrm{g} / \mathrm{mL}$ kanamycin at $37^{\circ} \mathrm{C}$ in humid air containing $5 \% \mathrm{CO}_{2}$. A673 was also purchased from American Type Culture Collection (Manassas, VA) and cultured in the same condition mentioned above. SYO-1 cell line provided by Dr. Akira Kawai (National Cancer Center Hospital, Tokyo, Japan) and Aska-SS and Yamato-SS cell 
lines provided by Dr. Norifumi Naka (Osaka International Cancer Center, Osaka, Japan) were cultured in the same condition.

\section{Ion torrent amplicon sequencing}

Genomic DNA was isolated from each cell line by DNeasy Blood \& Tissue Kit according to the manufacturer's protocols (QIAGEN, Hilden, Germany). Sequencing library construction and Ion torrent amplicon sequencing were performed via the TaKaRa Amplicon sequencing service by using the Ion Ampliseq Cancer Hotspot Panel v2, which includes primer sets to amplify 207 amplicons covering approximately 2,800 COSMIC mutations from 50 oncogenes and tumor suppressor genes using human hg19 reference genome as described in the manufacturer's web site (https://www.thermofisher.com/ order/catalog/product/4475346).

\section{Determination of drug efficacy in vitro}

Inhibitory effects of each agent against the sarcoma cell lines was assessed by using the sulforhodamine B (SRB) assay [56]. Percentage of growth was calculated using the following formula:

Percentage growth $(\%)=100 \times(\mathrm{T}-\mathrm{I}) /(\mathrm{C}-\mathrm{I})$

$\mathrm{T}$ : absorbance for the test well after incubation with drug for $48 \mathrm{~h}$

I: absorbance for the test and control well at starting point (addition of drugs),

C: absorbance for the control well (C) after incubation with vehicle for $48 \mathrm{~h}$

The drug concentration of the $\mathrm{GI}_{50}$ was calculated as described previously $(15,16)$. All drugs were tested in duplicate. The $\mathrm{GI}_{50}$ values were log transformed and were used for all analyses. Cluster analysis and visualization of heatmaps was performed using the Cluster 3.0 and TreeView software (Stanford University, CA, USA).

\section{Apoptosis detection}

Apoptosis was detected by Hoechst 33342 staining. Briefly, after incubation with ZSTK474 for $48 \mathrm{~h}$, the cells were trypsinized, collected and fixed in ice cold $1 \%$ glutarardehyde-PBS (-) at $4^{\circ} \mathrm{C}$ for $24 \mathrm{~h}$. After washing with PBS (-), the fixed cells were stained with $167 \mu \mathrm{M}$ Hoechst 33342 (Sigma-Aldrich, MO, USA), and observed via fluorescence microscopy. The number of the cells with nuclear condensation and DNA fragmentation was counted and the percentage of apoptotic cells relative to total cells was calculated. At least 100 cells were counted in each group.

\section{Animals}

Female nude mice with BALB/c genetic backgrounds (CAnN.Cg-Foxn1nu/CrlCrlj, 5 weeks old) were purchased from Charles River Japan, Inc. (Kanagawa, Japan), maintained under specific pathogen-free conditions in a 12:12 h light-dark cycle, and provided with sterile food and water ad libitium. Animal studies were performed in accordance with the procedures approved by the animal use and care committee of the Japanese Foundation for Cancer Research.

\section{Determination of drug efficacy in vivo}

Ectopic sarcoma xenograft models were previously established elsewhere by subcutaneous injection of SJCRH30 [57], SK-UT-1 [58], MES-SA [58], MES-SA/Dx5 [59], A673 [60] or SYO-1 [61] cells. Cells were resuspended in Hank's Balanced Salt Solution (Thermo Fisher Scientific, Waltham, MA) and subcutaneously transplanted into the back of nude mice. Animals were randomly assigned into test groups (each group containing 6 mice) and administration of drugs was performed on the day as indicated in each experiment. ZSTK474 was orally administrated daily at $400 \mathrm{mg} / \mathrm{kg}$ of body weight (BW) except for days 6 and 13 from the day of first administration (day 0). Pazopanib was orally administrated daily at $200 \mathrm{mg} / \mathrm{kg}$ of BW except for days 5, 6, 12 and 13 . Doxorubicin was intravenously injected weekly at $10 \mathrm{mg} /$ $\mathrm{kg}$ of BW. The control group mice were administrated with $5 \%$ HPMC. Antitumor effects were evaluated for 14 days in SJCRH30-, 14 days in SK-UT-1-, 10 days MES-SA-, 10 days in MES-SA/Dx5-, 14 days in A673-, 14 days in SYO-1- xenografted mice. Tumor volume was measured by calipers twice per week, and the tumor weight (TW) was calculated using the following formula:

$\mathrm{TW}=\left(\mathrm{L} \times \mathrm{W}^{2}\right) / 2$,

$\mathrm{L}$ : the longest dimension of the tumor

$\mathrm{W}$ : the width dimension of the tumor

The antitumor efficacy was evaluated by $\mathrm{T} / \mathrm{C}$, which was calculated using the following formula:

Treated/control ratio $[\mathrm{T} / \mathrm{C}](\%)=100 \times$ average $\mathrm{TW}$ of drug-treated group/average TW of control group.

\section{Immunoblot analysis}

Cells were washed with ice cold PBS (-) twice and lysed with $10 \mathrm{mM}$ Tris- $\mathrm{HCl}$ buffer at $\mathrm{pH} 7.4$ containing $50 \mathrm{mM} \mathrm{NaCl}, 50 \mathrm{mM} \mathrm{NaF}, 30 \mathrm{mM}$ sodium pyrophosphate, $50 \mathrm{mM} \mathrm{Na}_{3} \mathrm{VO}_{4}, 5 \mathrm{mM}$ EDTA, aprotinin at $100 \mathrm{Kal} \mathrm{U} / \mathrm{mL}$, $1 \mathrm{mM}$ phenylmethylsulfonyl fluoride, $0.5 \%$ Nonidet $\mathrm{P}-40$, and $0.1 \%$ sodium dodecyl sulfate (SDS). Tumor samples were resected from mice $4 \mathrm{~h}$ after the final drug administration, minced with scissors and homogenized by a glass homogenizer with a Teflon pestle in the same buffer described above. The protein concentration of each sample was measured by a BCA Protein Assay Kit (Thermo Fisher Scientific, Waltham, MA). Then, $10 \mu \mathrm{g}$ of lysate from each cell line or tissue was separated by SDS-polyacrylamide gel electrophoresis, and transferred 
onto a nitrocellulose membrane. After blocking with 5\% skim milk, the membrane was incubated with a primary antibody. Targeted antigens were detected by incubating with anti-phospho AKT (Ser473) antibody, anti-phospho AKT (Thr308) antibody, anti-pan AKT antibody, antiphospho S6 antibody, anti-S6 antibody, anti-phospho IGF1R $\beta$ (Tyr1135/1136) antibody, anti-phospho MEK 1/2 (Ser217/221) antibody, anti-phospho ERK 1/2 (Thr203/ Tyr204) antibody, anti-phospho 4E-BP1 (Thr37/46), antiAKT antibody, anti-S6 antibody, anti-cleaved PARP at Asp214 antibody, anti-PTEN antibody, anti-Id2 antibody, anti-GAPDH antibody (Cell Signaling Technologies, MA, USA), anti-phospho IGF-1R antibody (Abcam, Cambridge, UK) or anti- $\alpha$ tubulin antibody (SigmaAldrich, MO, USA), followed by fluorescently tagged secondary antibodies (Thermo Fisher Scientific, CA, USA). Visualization of bound antibody was carried out using fluorescently tagged secondary antibodies (Thermo Fisher Scientific, Waltham, MA) and the signals were detected and digitized by an Odyssey CLx Imaging System (LI-COR Corp., Lincoln, NE). An anti- $\alpha$ tubulin antibody (Sigma-Aldrich, St. Louis, MO) was used to provide data for a loading control.

\section{Luciferase reporter assay}

$1 \times 10^{6}$ of cells (RD-ES and A673) or $2.5 \times 10^{5}$ cells (HOS) were seeded into 6 well culture plates and cultured for $24 \mathrm{~h}$. Each cell was co-transfected with $1 \mu \mathrm{g}$ of pGL3-Id2-2755 and $1 \mu \mathrm{g}$ of Renilla (Renilla reniformis) luciferase internal control plasmid, pGL3-CMV (Promega Corporation, WI, USA) via the use of Lipofectamine 2000 (Thermo Fisher Scientific, CA, USA). The culture medium was changed after $6 \mathrm{~h}$ of transfection, and cells were passaged to a 96 well plate and treated with ZSTK474 at final concentrations of $0.3 \mu \mathrm{M}, 1 \mu \mathrm{M}, 3 \mu \mathrm{M}$ or $10 \mu \mathrm{M}$. Luciferase activity was detected using the Dual Glo Luciferase Assay System (Promega Corporation, WI, USA). The percentage of luciferase activity was calculated by the luciferase activity of firefly (Photinus pyralis) luciferase derived from pGL3-Id2-2755 divided by the Renilla luciferase from pGL3-CMV. pGL3-Id2-2755 was kindly gifted by Dr. Tokino [62].

\section{Immunohistochemistry}

Tumors were resected from mice, fixed with neutral formalin and embedded in paraffin. Four $\mu \mathrm{m}$ sections were cut and deparaffinized in xylene, followed by rehydration through a graded ethanol series (100\% to 50\%) to PBS (-). After incubation with Dako Real Target Retrieval Solution, pH 6 (Agilent Technologies, Santa Clara, CA) in boiling water bath for $40 \mathrm{~min}$, tumor sections were treated with $3 \% \mathrm{H}_{2} \mathrm{O}_{2}$ in PBS (-) and blocked with $10 \%$ normal goat serum. Following this, they were incubated with anti-p-S6 antibody, anti-cleaved PARP antibody
(Cell Signaling Technologies, MA, USA) or anti-CD31 antibody (Abcam, Cambridge, UK). The bound antibodies were visualized by using EnVision+System HRP labeled polymer antibody and DAB kit (Agilent Technologies, CA, USA), and the counterstaining was performed with hematoxylin. The number of nucleus of CD31-positive cell was counted as vascular endothelial cells.

\section{Statistical analysis}

Data was expressed as mean \pm SEM (in vivo studies, $n=6$ ). Statistical significance of antitumor efficacy was assessed by a Mann-Whitney $U$ test or Student's $t$ test or Welch $t$ test for comparison of two samples on days 10 (MES-SA and MES-SA/Dx5) and days 14 (SJCRH30, SK-UT-1, A673 and SYO-1). The statistical significance of observed anti-angiogenic effects was assessed by a Student's $t$ test for comparison of two samples. The statistical significance of aberrant gene status and protein expression levels was determined by either a MannWhitney $U$ test or Welch $t$ test. The statistical significance of luciferase activity was assessed by a Student's $t$ test. In all analyses, $P<0.05$ was considered statistically significant.

\section{Abbreviations}

JFCR: Japanese Foundation for Cancer Research; p-: phosphorylated-; EWSR1: Ewing sarcoma region 1; FLI1: Friend leukemia virus integration 1; PAX3: Paired box gene 3; FOXO1: Forkhead box O1A; SS18: synovial sarcoma translocation: chromosome 18; SSX: synovial sarcoma: X breakpoint; IHC: immunohistochemistry.

\section{Author contributions}

Conception and design: N.N., S.Y. and S.D. Development of methodology: N.N., N.T., Y.Y. and M.O. Acquisition of data: N.N., N.T., Y.Y., Y.N., K.Y., and M.O. Analysis and interpretation of data (e.g., statistical analysis, biostatistics, computational analysis): N.N. and M.O. Writing, review, and/or revision of the manuscript: N.N. and S.D. Administrative, technical, or material support (i.e., reporting or organizing data, constructing databases): M.T. and T.N. Study supervision: K.S., T.Y., S.Y., and S.D.

\section{ACKNOWLEDGMENTS}

We thank Dr. Takashi Tokino, Sapporo Medical University for providing us pLuciferase vector. We also thank Dr. Jumpei Enami, Zenyaku Kogyo Co. Ltd., Dr. Toshihiko Doi, National Cancer Center Hospital East, Dr. Shunji Takahashi, Cancer Institute Hospital of JFCR, and Dr. Tadashi Kondo, National Cancer Center Research Institute, for their kind support and helpful discussions. We thank Dr. Akira Kawai, National Cancer Center Hospital 
for providing us SYO-1 cell line and Dr. Norifumi Naka, Osaka International Cancer Center, for providing us AskaSS and Yamato-SS cell line, respectively. We would also like to express our gratitude to Y.Y.'s mentor, Prof. Isamu Shiina, Tokyo University of Science Graduate School of Science, for his guidance and giving a chance to Y.Y. to join our lab and perform the study.

\section{CONFLICTS OF INTEREST}

Ms. Nachi Namatame and Dr. Shinichi Yaguchi are employees of Zenyaku Kogyo Co., Ltd.

\section{FUNDING}

This work was supported in part by Practical Research for Innovative Cancer Control (16ck0106089s0203) from Japan Agency for Medical Research and Development, and a grant from National Cancer Center Research Development Fund (\#29-A-7).

\section{REFERENCES}

1. Jo VY, Fletcher CD. WHO classification of soft tissue tumours: an update based on the 2013 (4th) edition. Pathology. 2014; 46:95-104. https://doi.org/10.1097/ pat.0000000000000050.

2. Jemal A, Siegel R, Ward E, Hao Y, Xu J, Thun MJ. Cancer statistics, 2009. CA Cancer J Clin. 2009; 59:225-49. https:// doi.org/10.3322/caac.20006.

3. Miller RW, Young JL Jr, Novakovic B. Childhood cancer. Cancer. 1995; 75:395-405.

4. Linch M, Miah AB, Thway K, Judson IR, Benson C. Systemic treatment of soft-tissue sarcoma-gold standard and novel therapies. Nat Rev Clin Oncol. 2014; 11:187-202. https://doi.org/10.1038/nrclinonc.2014.26.

5. Helman LJ, Meltzer P. Mechanisms of sarcoma development. Nat Rev Cancer. 2003; 3:685-94. https://doi. org/10.1038/nrc1168.

6. Bonin G, Scamps C, Turc-Carel C, Lipinski M. Chimeric EWS-FLI1 transcript in a Ewing cell line with a complex $\mathrm{t}(11 ; 22 ; 14)$ translocation. Cancer Res. 1993; 53:3655-7.

7. Clark J, Rocques PJ, Crew AJ, Gill S, Shipley J, Chan AM, Gusterson BA, Cooper CS. Identification of novel genes, SYT and SSX, involved in the $\mathrm{t}(\mathrm{X} ; 18)(\mathrm{p} 11.2 ; \mathrm{q} 11.2)$ translocation found in human synovial sarcoma. Nat Genet. 1994; 7:502-8. https://doi.org/10.1038/ng0894-502.

8. Crew AJ, Clark J, Fisher C, Gill S, Grimer R, Chand A, Shipley J, Gusterson BA, Cooper CS. Fusion of SYT to two genes, SSX1 and SSX2, encoding proteins with homology to the Kruppel-associated box in human synovial sarcoma. EMBO J. 1995; 14:2333-40.

9. Skytting B, Nilsson G, Brodin B, Xie Y, Lundeberg J, Uhlén M, Larsson O. A Novel Fusion Gene, SYT-SSX4, in Synovial Sarcoma. J Natl Cancer Inst. 1999; 91:974-5. https://doi.org/10.1093/jnci/91.11.974.

10. May WA, Lessnick SL, Braun BS, Klemsz M, Lewis BC, Lunsford LB, Hromas R, Denny CT. The Ewing's sarcoma EWS/FLI-1 fusion gene encodes a more potent transcriptional activator and is a more powerful transforming gene than FLI-1. Mol Cell Biol. 1993; 13:7393-8.

11. Tanaka M, Yamazaki Y, Kanno Y, Igarashi K, Aisaki K, Kanno J, Nakamura T. Ewing's sarcoma precursors are highly enriched in embryonic osteochondrogenic progenitors. J Clin Invest. 2014; 124:3061-74. https://doi. org/10.1172/jci72399.

12. Haldar M, Hancock JD, Coffin CM, Lessnick SL, Capecchi MR. A conditional mouse model of synovial sarcoma: insights into a myogenic origin. Cancer Cell. 2007; 11:375-88. https://doi.org/10.1016/j.ccr.2007.01.016.

13. Taylor BS, Barretina J, Maki RG, Antonescu CR, Singer S, Ladanyi M. Advances in sarcoma genomics and new therapeutic targets. Nat Rev Cancer. 2011; 11:541-57. https://doi.org/10.1038/nrc3087.

14. Santoro A, Tursz T, Mouridsen H, Verweij J, Steward W, Somers R, Buesa J, Casali P, Spooner D, Rankin E. Doxorubicin versus CYVADIC versus doxorubicin plus ifosfamide in first-line treatment of advanced soft tissue sarcomas: a randomized study of the European Organization for Research and Treatment of Cancer Soft Tissue and Bone Sarcoma Group. J Clin Oncol. 1995; 13:1537-45. https:// doi.org/10.1200/jco.1995.13.7.1537.

15. Judson I, Verweij J, Gelderblom H, Hartmann JT, Schoffski P, Blay JY, Kerst JM, Sufliarsky J, Whelan J, Hohenberger P, Krarup-Hansen A, Alcindor T, Marreaud S, et al. Doxorubicin alone versus intensified doxorubicin plus ifosfamide for first-line treatment of advanced or metastatic soft-tissue sarcoma: a randomised controlled phase 3 trial. Lancet Oncol. 2014; 15:415-23. https://doi.org/10.1016/ s1470-2045(14)70063-4.

16. Erkizan HV, Kong Y, Merchant M, Schlottmann S, Barber-Rotenberg JS, Yuan L, Abaan OD, Chou TH, Dakshanamurthy S, Brown ML, Uren A, Toretsky JA. A small molecule blocking oncogenic protein EWS-FLI1 interaction with RNA helicase A inhibits growth of Ewing's sarcoma. Nat Med. 2009; 15:750-6. https://doi.org/10.1038/ nm.1983.

17. van der Graaf WT, Blay JY, Chawla SP, Kim DW, BuiNguyen B, Casali PG, Schoffski P, Aglietta M, Staddon AP, Beppu Y, Le Cesne A, Gelderblom H, Judson IR, et al. Pazopanib for metastatic soft-tissue sarcoma (PALETTE): a randomised, double-blind, placebo-controlled phase 3 trial. Lancet. 2012; 379:1879-86. https://doi.org/10.1016/ s0140-6736(12)60651-5.

18. Dickson MA, Tap WD, Keohan ML, D'Angelo SP, Gounder MM, Antonescu CR, Landa J, Qin LX, Rathbone DD, Condy MM, Ustoyev Y, Crago AM, Singer S, et al. Phase II trial of the CDK4 inhibitor PD0332991 in patients with advanced CDK4-amplified well-differentiated 
or dedifferentiated liposarcoma. J Clin Oncol. 2013; 31:2024-8. https://doi.org/10.1200/jco.2012.46.5476.

19. Luke JJ, D'Adamo DR, Dickson MA, Keohan ML, Carvajal RD, Maki RG, de Stanchina E, Musi E, Singer S, Schwartz GK. The cyclin-dependent kinase inhibitor flavopiridol potentiates doxorubicin efficacy in advanced sarcomas: preclinical investigations and results of a phase I dose-escalation clinical trial. Clin Cancer Res. 2012; 18:2638-47. https://doi.org/10.1158/1078-0432.ccr-11-3203.

20. Yoo C, Lee J, Rha SY, Park KH, Kim TM, Kim YJ, Lee HJ, Lee KH, Ahn JH. Multicenter phase II study of everolimus in patients with metastatic or recurrent bone and soft-tissue sarcomas after failure of anthracycline and ifosfamide. Invest New Drugs. 2013; 31:1602-8. https://doi. org/10.1007/s10637-013-0028-7.

21. Agulnik M, Yarber JL, Okuno SH, von Mehren M, Jovanovic BD, Brockstein BE, Evens AM, Benjamin RS. An open-label, multicenter, phase II study of bevacizumab for the treatment of angiosarcoma and epithelioid hemangioendotheliomas. Ann Oncol. 2013; 24:257-63. https://doi.org/10.1093/annonc/mds237.

22. Yamori T. [A human cell line panel for screening anti-cancer drugs]. [Article in Japanese]. Gan To Kagaku Ryoho. 1997; 24:129-35.

23. Dan S, Tsunoda T, Kitahara O, Yanagawa R, Zembutsu H, Katagiri T, Yamazaki K, Nakamura Y, Yamori T. An integrated database of chemosensitivity to 55 anticancer drugs and gene expression profiles of 39 human cancer cell lines. Cancer Res. 2002; 62:1139-47.

24. Yamori T. Panel of human cancer cell lines provides valuable database for drug discovery and bioinformatics. Cancer Chemother Pharmacol. 2003; 52: S74-9. https://doi. org/10.1007/s00280-003-0649-1.

25. Shoemaker RH. The NCI60 human tumour cell line anticancer drug screen. Nat Rev Cancer. 2006; 6:813-23. https://doi.org/10.1038/nrc1951.

26. Paull KD, Shoemaker RH, Hodes L, Monks A, Scudiero DA, Rubinstein L, Plowman J, Boyd MR. Display and analysis of patterns of differential activity of drugs against human tumor cell lines: development of mean graph and COMPARE algorithm. J Natl Cancer Inst. 1989; 81:1088-92.

27. Yaguchi S, Fukui Y, Koshimizu I, Yoshimi H, Matsuno T, Gouda H, Hirono S, Yamazaki K, Yamori T. Antitumor activity of ZSTK474, a new phosphatidylinositol 3-kinase inhibitor. J Natl Cancer Inst. 2006; 98:545-56. https://doi. org/10.1093/jnci/djj133.

28. Dan S, Yoshimi H, Okamura M, Mukai Y, Yamori T. Inhibition of PI3K by ZSTK474 suppressed tumor growth not via apoptosis but G0/G1 arrest. Biochem Biophys Res Commun. 2009; 379:104-9. https://doi.org/10.1016/j. bbrc.2008.12.015.

29. Dan S, Okamura M, Seki M, Yamazaki K, Sugita H, Okui M, Mukai Y, Nishimura H, Asaka R, Nomura K,
Ishikawa Y, Yamori T. Correlating phosphatidylinositol 3-kinase inhibitor efficacy with signaling pathway status: in silico and biological evaluations. Cancer Res. 2010; 70:4982-94. https://doi.org/10.1158/0008-5472. can-09-4172.

30. Dan S, Okamura M, Mukai Y, Yoshimi H, Inoue Y, Hanyu A, Sakaue-Sawano A, Imamura T, Miyawaki A, Yamori T. ZSTK474, a specific phosphatidylinositol 3-kinase inhibitor, induces G1 arrest of the cell cycle in vivo. Eur J Cancer. 2012; 48:936-43. https://doi. org/10.1016/j.ejca.2011.10.006.

31. Lockhart AC, Olszanski AJ, Allgren RL, Yaguchi S, Cohen SJ, Hilton JF, Wang-Gillam A, Shapiro GI. Abstract B271: A first-in-human Phase I study of ZSTK474, an oral pan-PI3K inhibitor, in patients with advanced solid malignancies. Molecular Cancer Therapeutics. 2013; 12:B271-B. https://doi.org/10.1158/1535-7163.targ-13-b271.

32. Valkov A, Kilvaer TK, Sorbye SW, Donnem T, Smeland E, Bremnes RM, Busund LT. The prognostic impact of Akt isoforms, PI3K and PTEN related to female steroid hormone receptors in soft tissue sarcomas. J Transl Med. 2011; 9:200. https://doi.org/10.1186/1479-5876-9-200.

33. Setsu N, Yamamoto H, Kohashi K, Endo M, Matsuda S, Yokoyama R, Nishiyama K, Iwamoto Y, Dobashi Y, Oda Y. The Akt/mammalian target of rapamycin pathway is activated and associated with adverse prognosis in soft tissue leiomyosarcomas. Cancer. 2012; 118:1637-48. https://doi.org/10.1002/cncr.26448.

34. Gutierrez A, Snyder EL, Marino-Enriquez A, Zhang YX, Sioletic S, Kozakewich E, Grebliunaite R, Ou WB, Sicinska E, Raut CP, Demetri GD, Perez-Atayde AR, Wagner AJ, et al. Aberrant AKT activation drives welldifferentiated liposarcoma. Proc Natl Acad Sci U S A. 2011; 108:16386-91. https://doi.org/10.1073/pnas.1106127108.

35. Friedrichs N, Trautmann M, Endl E, Sievers E, Kindler D, Wurst P, Czerwitzki J, Steiner S, Renner M, Penzel R, Koch A, Larsson O, Tanaka S, et al. Phosphatidylinositol3'-kinase/AKT signaling is essential in synovial sarcoma. Int J Cancer. 2011; 129:1564-75. https://doi.org/10.1002/ ijc. 25829 .

36. Hernando E, Charytonowicz E, Dudas ME, Menendez S, Matushansky I, Mills J, Socci ND, Behrendt N, Ma L, Maki RG, Pandolfi PP, Cordon-Cardo C. The AKTmTOR pathway plays a critical role in the development of leiomyosarcomas. Nat Med. 2007; 13:748-53. https://doi. org/10.1038/nm1560.

37. Giorgi C, Boro A, Rechfeld F, Lopez-Garcia LA, Gierisch ME, Schafer BW, Niggli FK. PI3K/AKT signaling modulates transcriptional expression of EWS/FLI1 through specificity protein 1. Oncotarget. 2015; 6:28895-910. https://doi.org/10.18632/oncotarget.5000.

38. Naka N, Takenaka S, Araki N, Miwa T, Hashimoto N, Yoshioka K, Joyama S, Hamada K, Tsukamoto Y, Tomita Y, Ueda T, Yoshikawa H, Itoh K. Synovial sarcoma is a stem 
cell malignancy. Stem Cells. 2010; 28:1119-31. https://doi. org/10.1002/stem.452.

39. Kong D, Okamura M, Yoshimi H, Yamori T. Antiangiogenic effect of ZSTK474, a novel phosphatidylinositol 3-kinase inhibitor. Eur J Cancer. 2009; 45:857-65. https://doi. org/10.1016/j.ejca.2008.12.007.

40. Isoyama S, Kajiwara G, Tamaki N, Okamura M, Yoshimi H, Nakamura N, Kawamura K, Nishimura Y, Namatame N, Yamori T, Dan S. Basal expression of insulin-like growth factor 1 receptor determines intrinsic resistance of cancer cells to a phosphatidylinositol 3-kinase inhibitor ZSTK474. Cancer Sci. 2015; 106:171-8. https://doi.org/10.1111/ cas. 12582 .

41. Barretina J, Taylor BS, Banerji S, Ramos AH, LagosQuintana M, Decarolis PL, Shah K, Socci ND, Weir BA, Ho A, Chiang DY, Reva B, Mermel CH, et al. Subtypespecific genomic alterations define new targets for softtissue sarcoma therapy. Nat Genet. 2010; 42:715-21. https://doi.org/10.1038/ng.619.

42. Joseph CG, Hwang H, Jiao Y, Wood LD, Kinde I, Wu J, Mandahl N, Luo J, Hruban RH, Diaz LA Jr, He TC, Vogelstein B, Kinzler KW, et al. Exomic analysis of myxoid liposarcomas, synovial sarcomas, and osteosarcomas. Genes Chromosomes Cancer. 2014; 53:15-24. https://doi. org/10.1002/gcc.22114.

43. Tanaka K, Iwakuma T, Harimaya K, Sato H, Iwamoto Y. EWS-Fli1 antisense oligodeoxynucleotide inhibits proliferation of human Ewing's sarcoma and primitive neuroectodermal tumor cells. J Clin Invest. 1997; 99:239 47. https://doi.org/10.1172/jci119152.

44. Fredericks WJ, Galili N, Mukhopadhyay S, Rovera G, Bennicelli J, Barr FG, Rauscher FJ 3rd. The PAX3FKHR fusion protein created by the $\mathrm{t}(2 ; 13)$ translocation in alveolar rhabdomyosarcomas is a more potent transcriptional activator than PAX3. Mol Cell Biol. 1995; 15:1522-35.

45. Kawai A, Naito N, Yoshida A, Morimoto Y, Ouchida M, Shimizu K, Beppu Y. Establishment and characterization of a biphasic synovial sarcoma cell line, SYO-1. Cancer Lett. 2004; 204:105-13.

46. Lessnick SL, Braun BS, Denny CT, May WA. Multiple domains mediate transformation by the Ewing's sarcoma EWS/FLI-1 fusion gene. Oncogene. 1995; 10:423-31.

47. Chansky HA, Barahmand-Pour F, Mei Q, Kahn-Farooqi W, Zielinska-Kwiatkowska A, Blackburn M, Chansky K, Conrad EU 3rd, Bruckner JD, Greenlee TK, Yang L. Targeting of EWS/FLI-1 by RNA interference attenuates the tumor phenotype of Ewing's sarcoma cells in vitro. J Orthop Res. 2004; 22:910-7. https://doi.org/10.1016/j. orthres.2003.12.008.

48. Carmody Soni EE, Schlottman S, Erkizan HV, Uren A, Toretsky JA. Loss of SS18-SSX1 inhibits viability and induces apoptosis in synovial sarcoma. Clin Orthop Relat Res. 2014; 472:874-82. https://doi.org/10.1007/ s11999-013-3065-9.
49. Fleuren EDG, Vlenterie $M$, van der Graaf WTA, Hillebrandt-Roeffen MHS, Blackburn J, Ma X, Chan H, Magias MC, van Erp A, van Houdt L, Cebeci SAS, van de Ven A, Flucke UE, et al. Phosphoproteomic Profiling Reveals ALK and MET as Novel Actionable Targets across Synovial Sarcoma Subtypes. Cancer Res. 2017; 77:427992. https://doi.org/10.1158/0008-5472.can-16-2550.

50. Imura $\mathrm{Y}$, Nakai $\mathrm{T}$, Yamada $\mathrm{S}$, Outani $\mathrm{H}$, Takenaka S, Hamada K, Araki N, Itoh K, Yoshikawa H, Naka N. Functional and therapeutic relevance of hepatocyte growth factor/c-MET signaling in synovial sarcoma. Cancer Sci. 2016; 107:1867-76. https://doi.org/10.1111/cas.13092.

51. Bai RY, Dieter P, Peschel C, Morris SW, Duyster J. Nucleophosmin-anaplastic lymphoma kinase of large-cell anaplastic lymphoma is a constitutively active tyrosine kinase that utilizes phospholipase C-gamma to mediate its mitogenicity. Mol Cell Biol. 1998; 18:6951-61.

52. Graupera M, Potente M. Regulation of angiogenesis by PI3K signaling networks. Exp Cell Res. 2013; 319:134855. https://doi.org/10.1016/j.yexcr.2013.02.021.

53. $\mathrm{Fu} \mathrm{Z}$, Tindall DJ. FOXOs, cancer and regulation of apoptosis. Oncogene. 2008; 27:2312-9. https://doi. org/10.1038/onc.2008.24.

54. Kummar S, Gutierrez M, Doroshow JH, Murgo AJ. Drug development in oncology: classical cytotoxics and molecularly targeted agents. Br J Clin Pharmacol. 2006; 62:15-26.

55. Rixe O, Fojo T. Is cell death a critical end point for anticancer therapies or is cytostasis sufficient. Clin Cancer Res. 2007; 13:7280-7.

56. Vichai V, Kirtikara K. Sulforhodamine B colorimetric assay for cytotoxicity screening. Nat Protoc. 2006; 1:1112-6. https://doi.org/10.1038/nprot.2006.179.

57. Waters AM, Stafman LL, Garner EF, Mruthyunjayappa S, Stewart JE, Mroczek-Musulman E, Beierle EA. Targeting Focal Adhesion Kinase Suppresses the Malignant Phenotype in Rhabdomyosarcoma Cells. Transl Oncol. 2016; 9:263-73. https://doi.org/10.1016/j.tranon.2016.06.001.

58. De Carvalho Fischer C, Hu Y, Morreale M, Lin WY, Wali A, Thakar M, Karunasena E, Sen R, Cai Y, Murphy L, Zahnow CA, Keer H, Thakar M, Ahuja N. Treatment with epigenetic agents profoundly inhibits tumor growth in leiomyosarcoma. Oncotarget. 2018; 9:19379-95. https:// doi.org/10.18632/oncotarget.25056.

59. Hung TH, Hsu SC, Cheng CY, Choo KB, Tseng CP, Chen TC, Lan YW, Huang TT, Lai HC, Chen CM, Chong KY. Wnt5A regulates ABCB1 expression in multidrug-resistant cancer cells through activation of the non-canonical PKA/beta-catenin pathway. Oncotarget. 2014; 5:12273-90. https://doi.org/10.18632/ oncotarget.2631.

60. Gerber HP, Kowalski J, Sherman D, Eberhard DA, Ferrara N. Complete inhibition of rhabdomyosarcoma xenograft growth and neovascularization requires blockade 
of both tumor and host vascular endothelial growth factor. Cancer Res. 2000; 60:6253-8.

61. Michels S, Trautmann M, Sievers E, Kindler D, Huss S, Renner M, Friedrichs N, Kirfel J, Steiner S, Endl E, Wurst P, Heukamp L, Penzel R, et al. SRC signaling is crucial in the growth of synovial sarcoma cells. Cancer Res. 2013; 73:2518-28. https://doi.org/10.1158/0008-5472. CAN-12-3023.
62. Nishimori H, Sasaki Y, Yoshida K, Irifune H, Zembutsu H, Tanaka T, Aoyama T, Hosaka T, Kawaguchi S, Wada T, Hata J, Toguchida J, Nakamura Y, et al. The Id2 gene is a novel target of transcriptional activation by EWS-ETS fusion proteins in Ewing family tumors. Oncogene. 2002; 21:8302-9. https://doi.org/10.1038/sj.onc.1206025. 